\title{
CIRURGIA ORTOGNÁTICA E POSTURA DA CABEÇA
}

\author{
VERA MARIA TELLES NUNES
}

Dissertação apresentada ao Hospital de Reabilitação de Anomalias Craniofaciais da Universidade de São Paulo, para obtenção do título de MESTRE em Ciências da Reabilitação.

Área de Concentração: Distúrbios da Comunicação Humana.

BAURU

2006 
UNIVERSIDADE DE SÃO PAULO

HOSPITAL DE REABILITAÇÃO DE ANOMALIAS CRANIOFACIAIS

\section{CIRURGIA ORTOGNÁTICA E POSTURA DA CABEÇA}

\section{VERA MARIA TELLES NUNES}

Orientador: Prof. Dr. Alceu Sergio Trindade Junior

Dissertação apresentada ao Hospital de Reabilitação de Anomalias Craniofaciais da Universidade de São Paulo, para obtenção do título de MESTRE em Ciências da Reabilitação.

Área de Concentração: Distúrbios da Comunicação Humana.

BAURU

2006 


\section{UNIVERSIDADE DE SÃO PAULO}

\section{HOSPITAL DE REABILITAÇÃO DE ANOMALIAS CRANIOFACIAIS}

R. Silvio Marchione, 3-20

Caixa Postal: 1501

17043-900 - Bauru - SP - Brasil

Telefone: (14) 3235-8000

Profa.Dra. Suely Vilela - Reitora da USP

Prof. Dr. José Alberto de Souza Freitas - Superintendente do HRAC-USP

Autorizo, exclusivamente, para fins acadêmicos e científicos, a reprodução total ou parcial desta dissertação.

Vera Maria Telles Nunes

Bauru, 03 de fevereiro de 2006.
N922c Cirurgia ortognática e postura da cabeça. /Vera Maria Telles Nunes. Bauru, 2006. 52p.; il.; $30 \mathrm{~cm}$.

Dissertação (Mestrado - Distúrbios da Comunicação Humana) - HRAC-USP

Orientador: Prof. Dr. Alceu Sergio Trindade Junior. Descritores: 1.Postura da cabeça.

2. Cirurgia maxilofacial. 3. Maloclusão. 
FOLHA DE APROVAÇÃO

Dissertação apresentada e defendida por

VERA MARIA TELLES NUNES

e aprovada pela Comissão Julgadora em 11

$\operatorname{Prof}(a) \cdot \operatorname{Dr}(a) .:$

Instituição:

$\operatorname{Prof}(a) \cdot \operatorname{Dr}(a):$

Instituição:

Prof(a).Dr(a).:

Instituição:

Profa.Dra. Inge Elly Kiemle Trindade

Presidente da Comissão de Pós-Graduação do HRAC-USP

Data de depósito da dissertação junto à CPG: 1 


\section{VERA MARIA TELLES NUNES}

11 de março de 1956

Nascimento.

Bauru - SP

1976-1979 Curso de Fisioterapia - Pontifícia Universidade Católica de Campinas - SP.

1980-2006

Atuação clínica como Fisioterapeuta em Bauru - SP.

1989-1995

Programa de Aprimoramento em Fisioterapia, no Hospital de Pesquisa e Reabilitação de Lesões Lábio-Palatais da Universidade de São Paulo.

1993

Curso de Aperfeiçoamento em

Fisiopatologia Craniocervical,

Craniomandibular e Dor Facial no CEDIME, em Santiago-Chile.

1997-2006

Professora e Coordenadora Local do curso de Fisioterapia da Universidade Paulista (UNIP), campus Bauru.

Associações

SOBRAD - Sociedade Brasileira de ATM e Dor Orofacial. 
Dedico este trabalho aos meus pais, José Carlos e Vera, que não mediram esforços e sempre me incentivaram a trilhar o caminho do saber, fazendo com que eu reagisse às adversidades, colhendo os bons frutos do conhecimento e da amizade de pessoas, que passaram a fazer parte da minha história. 


\section{Agradecimentos \\ Especiais}


Agradeço, especialmente, a Deus, por sua benevolência para com a minha vida e dos meus entes mais queridos.

Agradeço ao Prof. Dr. Alceu Sergio Trindade Jr., o qual admiro, não somente por sua competência profissional, mas também pela disponibilidade, dedicação e amizade demonstradas ao longo da realização deste trabalho.

Agradeço ao meu companheiro Evandro e aos meus filhos Paulinho e Álvaro, por compreenderem minha ausência em alguns momentos.

Agradeço à Trixy, que foi não só amiga, mas também companheira, colaboradora incansável, sempre pronta a ajudar quando e o quanto fosse necessário. Sua serenidade e dedicação me transmitiram segurança e me fizeram acreditar que seria possível concluir este trabalho. Serei sempre grata por poder conviver com você. 


\section{Agradecimentos}


AGRADEÇO

Ao Prof. Dr. José Alberto de Souza Freitas, superintendente do HRAC-USP por seu exemplo em administrar o Centrinho, fazendo com que os pacientes e seus familiares sejam recebidos com carinho e igualdade.

À Dra. Inge Elly Kiemle Trindade, por sua seriedade na atuação como Presidente da Pós-Graduação do HRAC-USP, demonstrando, além de conhecimento, preocupação com seus alunos e membros do Programa.

À Profa. Dra. Katia Flores Genaro, por seu interesse em ajudar no desenvolvimento desse trabalho, esclarecendo dúvidas sobre os aspectos fonoaudiológicos, e pelo carinho em todos os momentos que convivemos.

À banca do exame de qualificação, nas pessoas de Prof. Dr. Roberto Loureiro Maringoni, Profa. Dra. Katia Flores Genaro e Profa. Dra. Renata Paciello Yamashita, pelas correções e sugestões feitas para o aprimoramento deste trabalho.

À Melina, pela amizade e paciência, demonstradas, principalmente, nas aulas de Estatística (Pacotico).

À Andréia, do Setor de Pós-Graduação, por seu carinho e atenção, durante todo esse período que passamos juntas.

À todo o pessoal do Setor de Pós-Graduação, Rogério, Saulo, Zezé, por sempre nos receberem com um sorriso e disponibilidade.

À Renata, Ana Claudia e Ana Paula, por todo carinho, colaboração e também pelos bons momentos no Laboratório de Fisiologia. 
Às meninas da Especialização, Tati, superMillena, Sylvia, Roberta, Paola e Vivian, pelo bom humor, e também à Carol, Lú, Adriana, Juliana, por estarem sempre dispostas a trocar idéias e sugestões sobre o Trabalho.

A todo o pessoal do arquivo, pela atenção e colaboração.

A todas as meninas da UEP, por estarem sempre disponíveis para esclarecimentos.

À Gisele Dalben, pela ajuda, amizade e profissionalismo.

Ao Edson, pela atenção e auxílio nas fotos do trabalho.

Ao Bruno, por ter colaborado como modelo para as fotografias apresentadas.

Aos pacientes, que aceitaram participar da pesquisa, fazendo com que fosse possível a realização deste estudo.

Aos professores do Programa de Pós-Graduação e toda equipe do HRACUSP. 
Sumário 


\section{SUMÁRIO}

RESUMO i

ABSTRACT ii

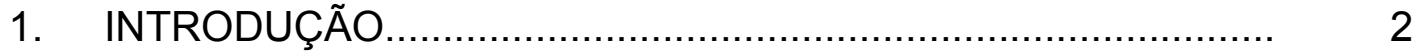

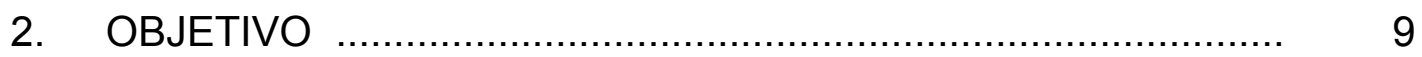

3 MATERIAL E MÉTODO

3.1 Casuística e procedimentos .................................... 11

3.2 Critério para análise dos dados ....................................... 20

4. RESULTADOS …......................................................... 24

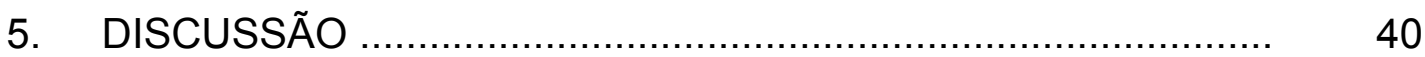

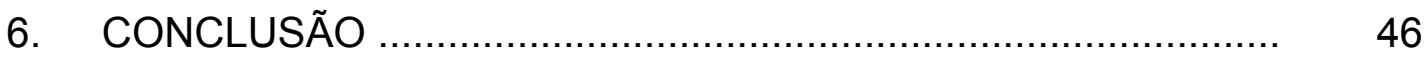

7. REFERÊNCIAS BIBLIOGRÁFICAS .................................... 48 ANEXOS 


\section{RESUMO}

Nunes VMT. Cirurgia ortognática e postura da cabeça [dissertação]. Bauru: Hospital de Reabilitação de Anomalias Craniofaciais, Universidade de São Paulo; 2006.

Objetivo: A postura de cabeça relaciona-se com o equilíbrio do sistema estomatognático podendo alterar-se em casos de deformidades dentofaciais com indicação cirúrgica. Dessa forma, o presente estudo teve por objetivo verificar se a cirurgia ortognática, realizada para corrigir a deformidade dentofacial, caracterizada por mordida cruzada total, leva, a curto prazo, à modificação na postura de cabeça de indivíduos com fissura labiopalatina.

Modelo: Utilizou-se um protocolo específico de anamnese e avaliação visual da postura da cabeça, da coluna cervical e da altura do ombro, da tonicidade muscular e da presença de dor à palpação.

Local: Laboratório de Fisiologia - HRAC/USP.

Participantes: Foram avaliados 6 indivíduos, 3 de cada gênero, entre 19 e 33 anos, com mordida cruzada total e fissura labiopalatina reparada antes e, em média, 4 meses após a cirurgia ortognática.

Resultados: Não foram detectadas alterações importantes nos parâmetros avaliados.

Conclusão: Assim, pode-se concluir que, na amostra avaliada, não houve modificação na postura da cabeça após a cirurgia ortognática nos indivíduos com fissura labiopalatina e mordida cruzada. 


\begin{abstract}
Nunes VMT. Orthognathic surgery and head posture. [dissertation]. Bauru: Hospital for Rehabilitation of Craniofacial Anomalies, University of Sao Paulo; 2006.
\end{abstract}

Objective: Head posture is related to the balance of the stomathognathic system and may be altered in individuals with dentofacial deformities in need of surgical treatment. Thus, the present study investigated if orthognathic surgery performed to correct dentofacial deformities characterized by complete crossbite leads to short-term changes in head posture of individuals with cleft lip and palate.

Design: A specific protocol was followed, including anamnesis, visual assessment of head posture, cervical spine and shoulder height, muscle tonicity and muscle pain to palpation.

Setting: Physiology Laboratory - HRAC/USP.

Subjects: The sample comprised six individuals, being 3 males and 3 females, aged 19 to 33 years, presenting complete crossbite and repaired cleft lip and palate. Patients were assessed before and approximately 4 months after orthognathic surgery.

Results: No important alterations were observed in the study parameters. Conclusion: Thus, it could be concluded that there were no changes in head posture after orthognathic surgery in the present sample of individuals with cleft lip and palate and crossbite. 
Introdução 


\section{INTRODUÇÃO}

A fisioterapia, acompanhando a evolução do conhecimento científico na área das ciências da saúde, vem aprimorando sua atuação e procedimentos quanto à prevenção, o diagnóstico e o tratamento das estruturas envolvidas com o movimento corporal humano. Deste modo, contribui e interrelaciona-se com outras áreas como a fonoaudiologia e a odontologia, auxiliando no restabelecimento e adequação das funções do sistema estomatognático.

Para que esse sistema desempenhe suas funções adequadamente, é necessário que haja harmonia entre todos os seus componentes, o que proporcionará equilíbrio de pressões relacionadas às estruturas ósseas e musculares, permitindo um bom desempenho da sucção, deglutição, mastigação, respiração e fala, além da postura da cabeça e posição habitual da língua e dos lábios durante o repouso (Berretin-Felix et al 2004).

O sistema estomatognático é uma unidade morfofuncional anatomicamente integrada e fisiologicamente coordenada (Rocabado 1979), formada por estruturas estáticas, como os arcos dentários, a maxila e a mandíbula relacionadas pelas articulações temporomandibulares, os ossos cranianos e o osso hióide; além das estruturas dinâmicas, formadas pelas unidades neuromusculares (Zemlin 2000 e Douglas 2002). Desse modo, esse sistema relaciona-se com as estruturas anatômicas da cabeça e do pescoço e, de acordo com Krakauer (1997) devem ser avaliados e tratados integralmente, uma vez que mudanças na posição da cabeça como as alterações posturais antero-posteriores afetam o equilíbrio de forças da mandíbula e influenciam no fechamento mandibular (Goldstein et al 1984).

A relação funcional do sistema estomatognático está determinada pela estabilidade postural ortostática do crânio sobre a coluna cervical (Rocabado 1979). A região crânio-cervico-mandibular corresponde a uma unidade anatomofuncional indivisível, dinâmica, que trabalha organizada seqüencialmente e integrada a todo o organismo (San Juan Zamora et al 1999).

De acordo com Kinser e Colby (1989), postura é o arranjo relativo das partes do corpo para uma atividade específica ou a maneira característica pela 
qual o indivíduo sustenta o corpo. Já Kendall (1995), define postura como o resultado do alinhamento de todas as articulações do corpo, considerando o alinhamento da coluna superior essencial para o bom alinhamento da cabeça e pescoço, deixando a cabeça em posição bem equilibrada e mantida com o mínimo esforço muscular. Considera, também, que o tórax e a coluna superior permanecem em posição que favorece a função ideal dos órgãos respiratórios.

Tanaka e Farah (1997) afirmaram que a postura é o arranjo que os seguimentos do corpo mantém entre si em determinada posição, a fim de proporcionar conforto, harmonia, economia e sustentação durante o movimento. Referiram que a coluna cervical é composta por dois seguimentos: o superior ( $\mathrm{C} 1$ e $\mathrm{C} 2$ ) e o inferior ( $\mathrm{C} 3$ à $\mathrm{C} 7)$ que, do ponto de vista funcional, esta divisão permite distinguir os movimentos da cabeça e do pescoço.

Assim sendo, os movimentos do pescoço são basicamente compostos por flexão, extensão, rotação lateral direita e esquerda e inclinação lateral direita e esquerda. A combinação destes movimentos proporciona à cabeça $\mathrm{e}$ ao pescoço vários outros movimentos, permitindo ampla mobilidade. Dos movimentos de flexão e extensão, aproximadamente metade destes realiza-se entre a região occipito e $\mathrm{C} 1$, enquanto a outra metade distribui-se por outras vértebras cervicais. Já, metade dos movimentos de rotação ocorrem entre $\mathrm{C} 1 \mathrm{e}$ $\mathrm{C} 2$ e, a outra metade, distribui-se por meio das outras vértebras cervicais. Quanto ao movimento de inclinação lateral, este não é um movimento puro, mas a conjunção de funções de todas as vértebras cervicais e de elementos de rotação (Hoppenfeld 1999).

Bricot (1999) considera que o sistema postural é um "todo estruturado", com entradas múltiplas, tendo muitas funções complementares como: lutar contra a gravidade e manter a postura ereta, opor-se a forças externas, situarnos no espaço/tempo estruturado que nos envolve, guiar e reforçar o movimento, além de equilibrar-nos durante o mesmo. De acordo com esse autor, alguns aspectos relacionados ao equilíbrio são indispensáveis para uma boa função. Assim, para a harmonia craniofacial é necessário que haja simetria do plano frontal, das três regiões da face, das linhas bipupilares e da linha entre os tragus, além de fenda labial paralela e horizontal. Já, na visão de perfil, as três regiões faciais devem estar harmoniosas, sem recuos ou 
projeções. Articulações equilibradas e simétricas nos três planos do espaço são necessárias, além dos músculos apresentarem tensões similares bilateralmente e não haver falta de elementos dentários ou contato prematuro. Além disso, a língua deve apresentar-se centralizada e a respiração deve ser por via nasal durante o repouso.

Sabe-se que a oclusão influencia na posição da mandíbula, determinando a posição do crânio sobre a coluna cervical. Quando a cabeça está em flexão, o contato oclusal é anterior e, quando está em extensão, o contato é posterior. Além disso, quando a cabeça está rodada ou inclinada, observa-se que o contato oclusal ocorre para o lado da inclinação ou da rotação.

Deste modo, qualquer ajuste oclusal poderá causar efeitos compensatórios por meio da cadeia postural, levando o corpo a adotar uma nova postura. Assim, esta informação deveria ser considerada no planejamento dos tratamentos odontológicos que necessitam de ajuste oclusal (MacConkey 1991).

A postura anteriorizada de cabeça influencia, estrutural e funcionalmente, o sistema estomatognático, uma vez que pode alterar o desenvolvimento craniofacial e a morfologia óssea e neuromuscular. Além disso, a posição postural craniocervical está relacionada com a posição postural da mandíbula, que é a base do sistema estomatognático (Gonzales e Manns 1996). Em toda alteração da posição da cabeça ocorre compensação mandibular, com má oclusão dentária e conseqüente alteração funcional da mastigação e deglutição (Tessitori 2004).

Assim, a postura de cabeça e pescoço está associada à ocorrência de má oclusão (Solow e Sonnesen 1998). A má oclusão Classe II de Angle (1907), altera a posição da cabeça e dos ombros para frente e, na má oclusão Classe III de Angle, ocorre deslocamento da cabeça para trás, conforme ilustra a figura 1. Já, a mordida cruzada unilateral é considerada a principal causa de distúrbios tridimensionais, tendo como conseqüências posturais as básculas e 
rotações com alterações intervertebrais menores em alguns segmentos (Bricot 1999).

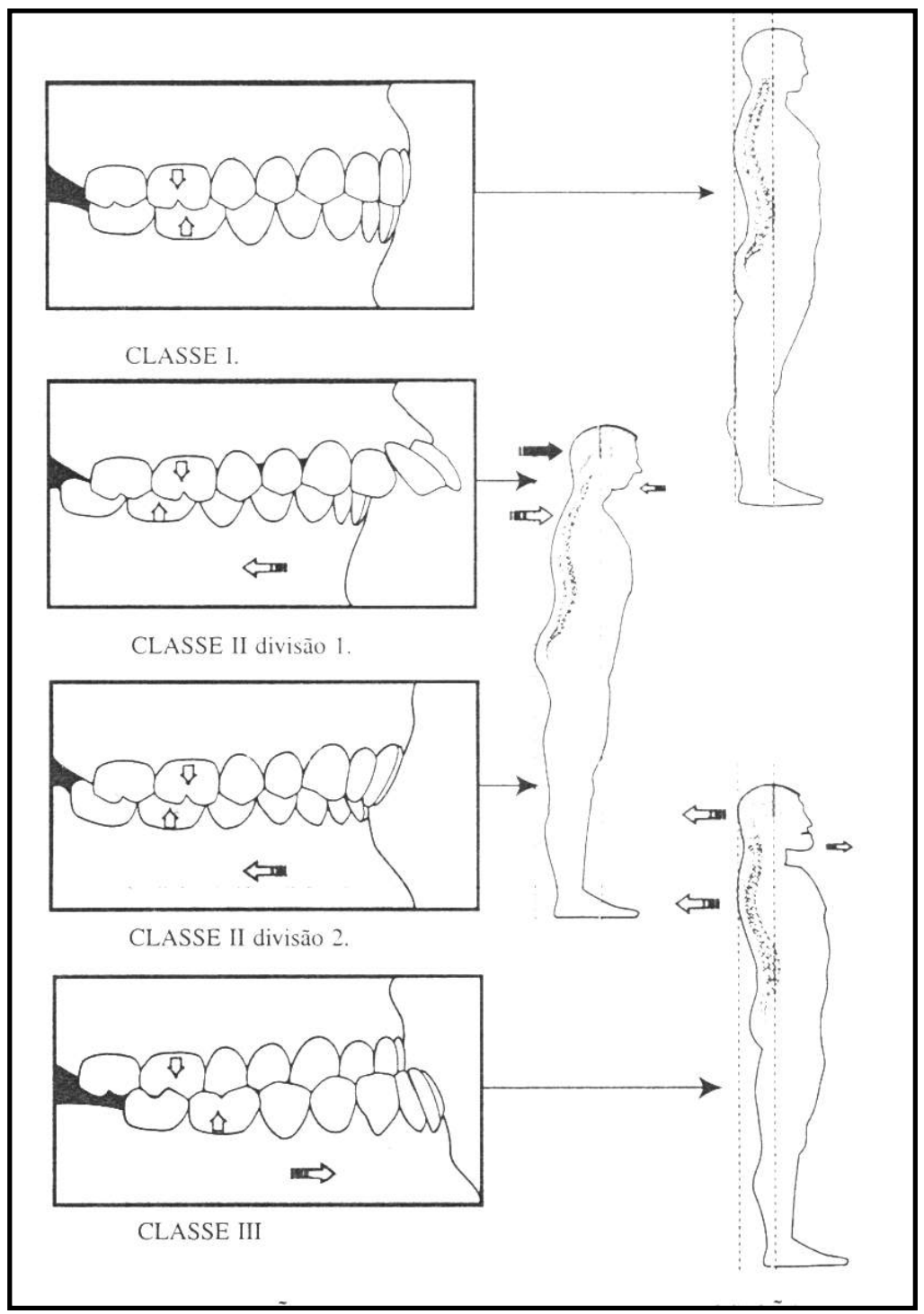

Bricot (1999)

Figura 1. Relação entre postura e má oclusão 
Embora haja evidência da correlação entre postura da cabeça e má oclusão, os tratamentos não devem ser realizados concomitantemente (Michelotti et al 1999), uma vez ter sido constatado que indivíduos com flutuação na atitude postural dinâmica enquanto submetidos ao uso do MORA (Mandibular Orthopedic Repositioning Appliances - Aparelho de Reposicionamento Mandibular Ortopédico) tiveram diminuição gradativa desta flutuação após a retirada do mesmo (Milani et al 2000).

A relação entre má oclusão e postura de cabeça pode não ser unicamente devido ao equilíbrio ortostático do crânio sobre a coluna cervical, mas também estar associada à alteração da respiração, presente na maioria dos indivíduos com problemas oclusais. Estudo realizado mostrou que a obstrução do nariz resulta em progressiva extensão da cabeça após 1 hora ou 1 hora e meia, obtendo-se respostas em todos os indivíduos, que variou apenas quanto ao grau e quanto à velocidade. Após a retirada da obstrução nasal, a postura da cabeça retornou à normalidade (Vig et al 1980).

Estando o mecanismo respiratório alterado, poderá interferir na posição de repouso mandibular e no alinhamento crânio cervical, causando aumento da compressão nas articulações sub-occipitais e temporomandibulares, aumento da intercuspidação posterior e aumento da lordose cervical (Hruska 1997).

As situações de compensação do sistema estomatognático, podem ser encontradas em casos específicos, como é o caso da alteração postural observada nos indivíduos com respiração bucal, os quais realizam uma rotação posterior do crânio para favorecer a entrada de ar pela cavidade bucal, ocasionando assim, aumento da cifose torácica com aproximação dos ombros e fechamento do tórax e alterando o ritmo respiratório para diminuir os efeitos do impacto do ar na faringe. As cadeias musculares orofaciais e corporais, por sua vez, inter-relacionam-se funcionalmente mediante sinergia neuromuscular, além da postura crânio-oro-facial, em relação à postura corporal, ter ligação importante com a função respiratória e esta com as demais funções desempenhadas pelo sistema estomatognático (Tessitori 2004).

Nos casos em que a má oclusão envolve desproporção óssea entre a mandíbula e a maxila, configurando uma deformidade dentofacial, principalmente em indivíduos que ultrapassaram o período de crescimento, faz- 
se necessário a intervenção cirúrgica. A cirurgia ortognática é um procedimento que tem por objetivo de restabelecer o equilíbrio funcional dos componentes do sistema estomatognático e a harmonia facial (Souza et al 1997 e Peterson et al 2000).

Nesse sentido, destacam-se os casos com deformidade dentofacial decorrentes da fissura labiopalatina reparada, cuja correção requer procedimentos ortodôntico-cirúrgicos, a fim de corrigir tanto a estética facial como a funcionalidade do sistema estomatognático.

Diante da correção da deformidade dentofacial por meio da cirurgia ortognática pode haver ou não modificação na postura de cabeça. Na literatura, há trabalhos que encontraram modificação nessa postura após a cirurgia. Dependendo do tipo de procedimento cirúrgico realizado, há alteração na flexão, enquanto mudança significante não foi encontrada na postura do pescoço (Phillips et al 1991).

Benech et al (1997), estudaram a avaliação postural do paciente antes e após a cirurgia ortognática, tendo por objetivo averiguar se a mudança na oclusão após a cirurgia ortognática pode alterar a postura do paciente. As avaliações foram feitas em 15 casos com dismorfia facial, antes e seis meses após a cirurgia ortognática, levando-se em consideração a postura e os sintomas craniomandibulares. Observaram na avaliação pré-cirúrgica grande ocorrência de casos com assimetria postural frontal e sintomas de disfunção craniomandibular. Nas avaliações pós-cirúrgicas notaram que com a readaptação da oclusão dentária, houve melhora da postura corporal frontal, reduzindo, também, a intensidade dos sintomas de disfunção craniomandibular. Relataram, também, melhora da estética facial.

Tendo em vista a escassez de estudos relacionando a postura de cabeça com a cirurgia ortognática e, tendo esses indivíduos fissura labiopalatina previamente reparada e mordida cruzada total (má oclusão comprometida nos sentidos anteroposterior e transversal), o presente estudo pretende contribuir com as pesquisas sobre essa relação. 


\section{Objetivo}




\section{OBJETIVO}

O presente estudo teve por objetivo verificar se a cirurgia ortognática, realizada para corrigir a deformidade dentofacial, caracterizada por mordida cruzada total, leva, a curto prazo, à modificação na postura de cabeça de indivíduos com fissura labiopalatina 
Material e

Método 


\section{MATERIAL E MÉTODO}

\subsection{Casuística e Procedimentos}

Este trabalho foi realizado no Laboratório de Fisiologia do Hospital de Reabilitação de Anomalias Craniofaciais da Universidade de São Paulo (HRAC/USP), após a aprovação do projeto de pesquisa pelo comitê de Ética em Pesquisa com Seres Humanos desta Instituição (anexo 1).

Todos os indivíduos que participaram deste estudo foram informados sobre os procedimentos da pesquisa por meio da Carta de Informação ao Paciente (anexo 2) e assinaram o Termo de Consentimento Livre e Esclarecido (anexo 3).

A coleta de dados foi realizada de julho de 2004 à maio de 2005, totalizando 8 casos avaliados na fase pré-cirúrgica ( 2 a 3 dias antes da cirurgia). Entretanto, desses, 2 casos não puderam ser avaliados na fase póscirúrgica, em média 4 meses após a cirurgia, pois 1 deles desistiu de realizar a cirurgia e o outro não atendeu ao retorno previsto. Assim sendo, a amostra final contou com 6 casos, sendo 3 do gênero feminino e 3 do gênero masculino, com idade entre 19 e 33 anos, que faziam parte da rotina dos atendimentos do Laboratório de Fisiologia do HRAC/USP.

Todos apresentavam fissura labiopalatina reparada cirurgicamente, sendo 4 com fissura transforame incisivo unilateral (2 à esquerda e 2 à direita), 1 com fissura transforame incisivo bilateral e o outro com fissura pós-forame incisivo, todos apresentando mordida cruzada total (figura 2), sendo que 1 indivíduo apresentava, também, mordida aberta anterior.

Quanto ao tipo de cirurgia ortognática realizada, todos foram submetidos ao avanço da maxila, sendo em um caso associada à correção de prognatismo mandibular. Como critérios de exclusão, foi considerado a presença de alterações neurológicas, genéticas e doenças sistêmicas, verificada pela análise do prontuário do paciente. 


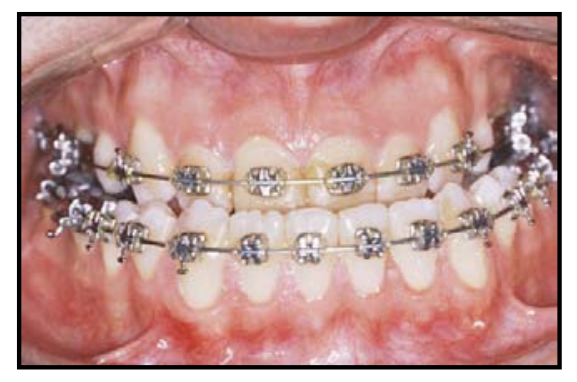

Figura 2. Visão frontal intra-oral da mordida cruzada total.

Para cada paciente da amostra foram realizadas avaliações nas fases pré e pós-cirúrgica. Para fins de coleta de dados foi elaborado um protocolo (anexo 4), o qual era preenchido durante as avaliações nas duas fases. Esse protocolo continha informações sobre a identificação do paciente, a saúde geral, bem como avaliação específica da postura da cabeça e da coluna cervical, tonicidade muscular, presença de dor à palpação e da altura dos ombros.

Especificamente em relação à inspeção da postura da cabeça, foi verificado a linha bipupilar, a cabeça face anterior, a cabeça face lateral e a mobilidade ativa da cabeça, encontrando-se o indivíduo com o tronco despido, sentado em uma cadeira com assento e espaldar em madeira, sem inclinações, em posição habitual de cabeça. Todos esses itens são descritos a seguir: 
Linha bipupilar (figura 3): O examinador observou visualmente o paciente em posição natural da cabeça, verificando se as pupilas encontravam-se na mesma altura ou se havia o rebaixamento de uma delas, identificando o lado em que esta ocorria, segundo os critérios descritos por Bricot (1999).

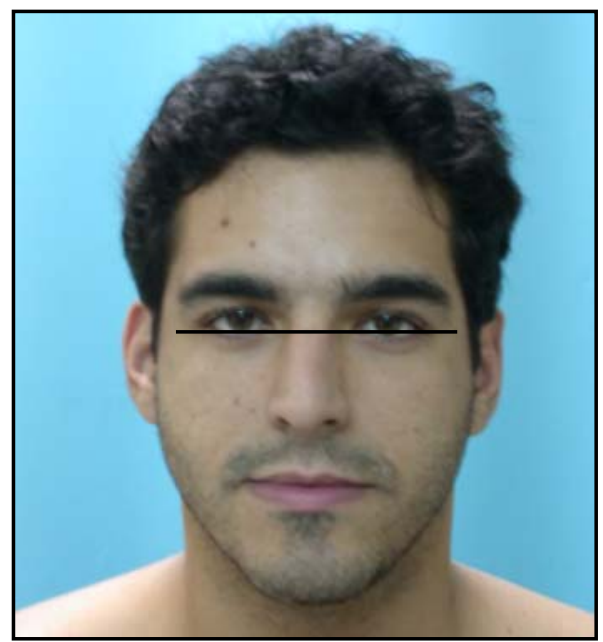

Figura 3. Avaliação da linha bipupilar. 
Cabeça face anterior (figura 4): A face do indivíduo foi observada olhando-se de frente, se a cabeça encontrava-se centralizada, rodada ou inclinada lateralmente, segundo a descrição de Hoppenfeld (1999).

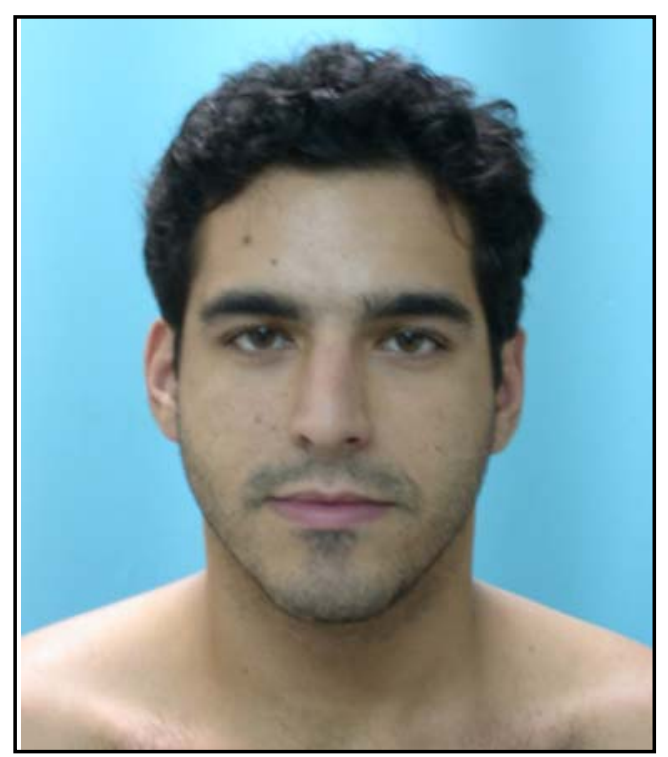

Figura 4. Avaliação da cabeça face anterior. 
Cabeça face lateral (figura 5): Observou-se a cabeça de perfil, a fim de se verificar se esta encontrava-se normal, protruída, em extensão ou em flexão, conforme descrição de Hoppenfeld (1999).

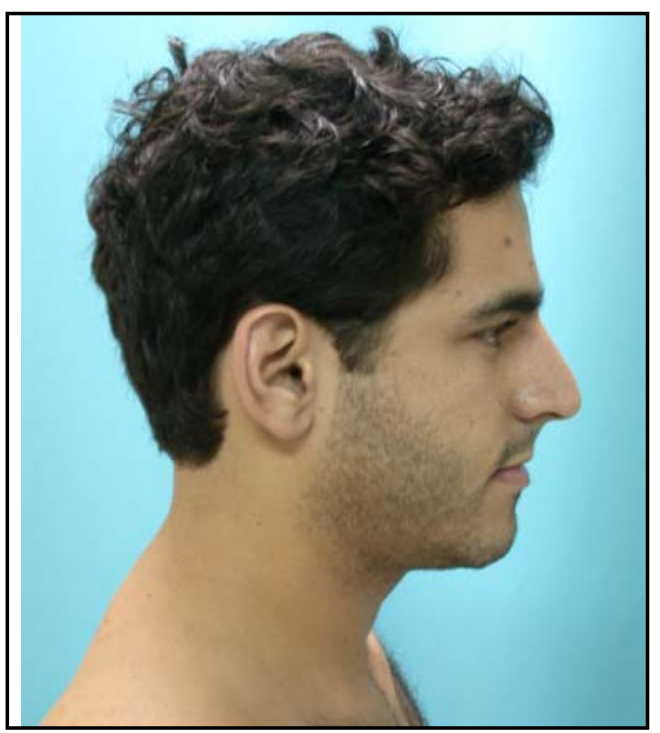

Figura 5. Avaliação da cabeça face lateral. 
Coluna cervical: Já, em relação à coluna cervical (figura 6) verificou-se o perfil desta, compreendendo a presença de lordose fisiológica, retificação da lordose ou hiperlordose cervical, segundo a classificação da avaliação de Hoppenfeld (1999).

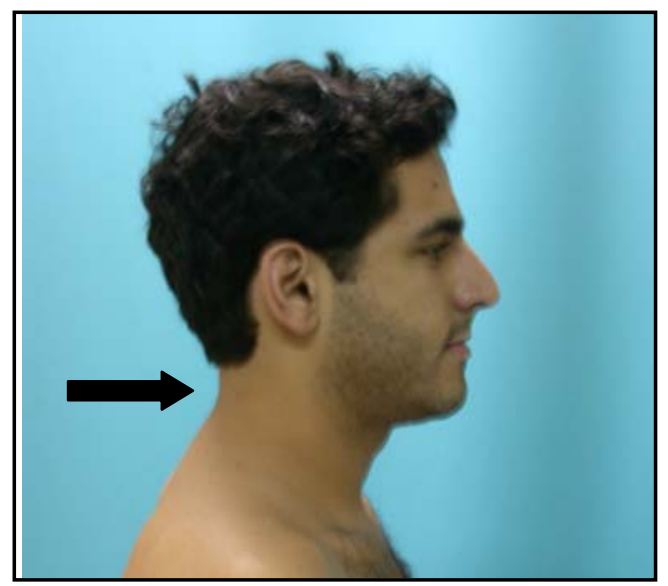

Figura 6. Avaliação da coluna cervical. 
Tonicidade: Também foi verificado, por meio de palpação, a tonicidade dos músculos masseteres, trapézios e esternocleidomastóideos.

Para verificar a mobilidade ativa da cabeça, fora observado os movimentos de flexão (figura 7) e extensão (figura 8), rotação para a direita (figura 9) e para a esquerda, bem como a inclinação lateral para direita (figura 10) e para a esquerda, tendo sido solicitado ao indivíduo que realizasse 3 movimentos em cada direção, a fim de confirmar a normalidade ou a limitação dos movimentos, seguindo Hoppenfeld (1999).

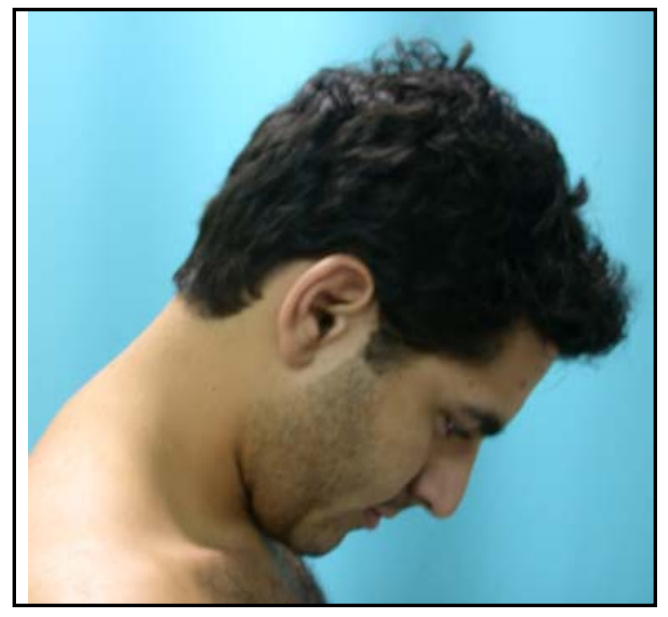

Figura 7. Avaliação da flexão da cabeça.

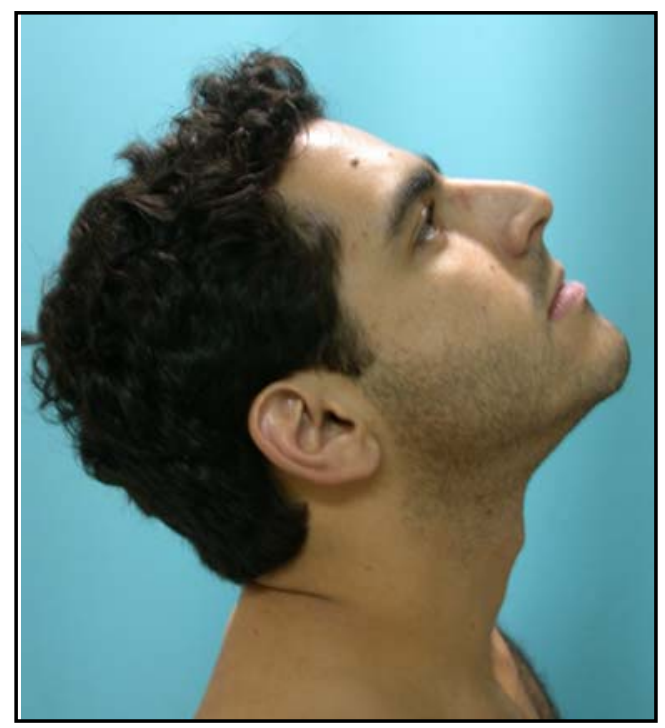

Figura 8. Avaliação da extensão da cabeça. 


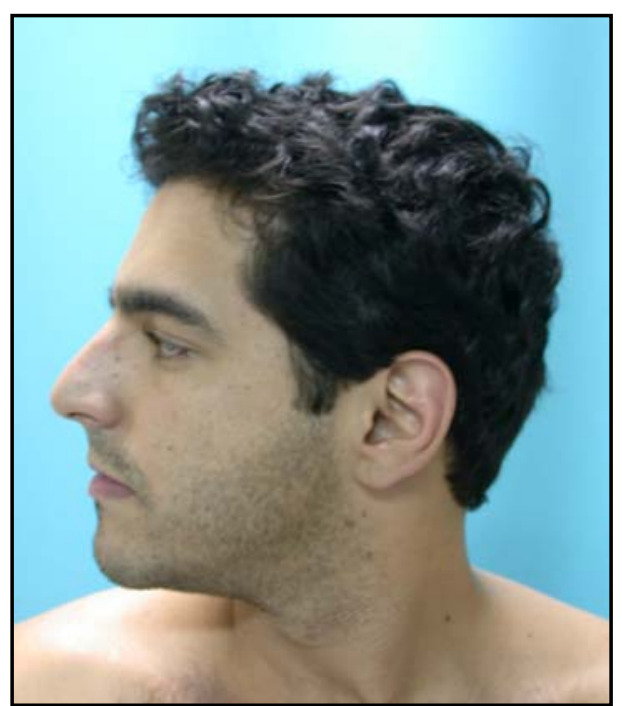

Figura 9. Avaliação da rotação da cabeça (direita).

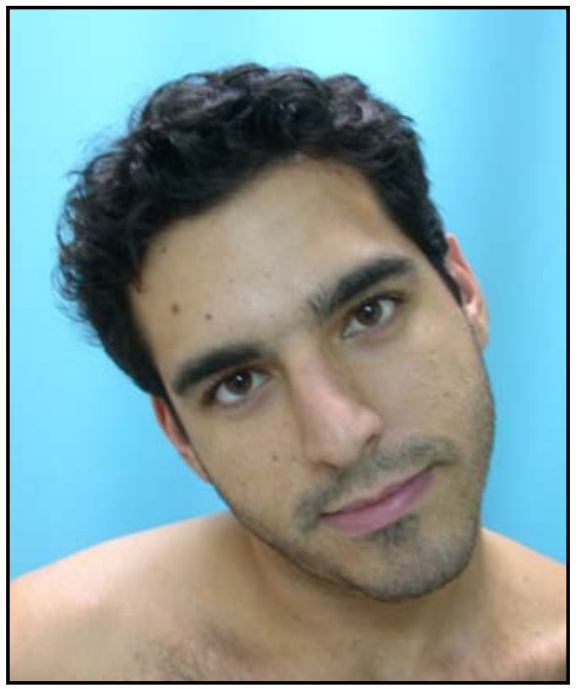

Figura 10. Avaliação da inclinação lateral da cabeça (direita). 
Sintomatologia dolorosa: Por meio de palpação digital, pode ser verificado a presença de sintomatologia dolorosa nos músculos trapézios, esternocleidomastoídeos e articulações temporomandibulares. Foi questionado ao indivíduo, se, durante a pressão exercida sobre a região avaliada, era percebido sensação dolorosa (Hoppenfeld 1999).

Altura dos ombros: A altura dos ombros foi verificada, visualmente, com o paciente posicionado da mesma forma descrita anteriormente, sendo analisado se havia diferença na altura dos ombros, conforme Hoppenfeld (1999) (figura 11).

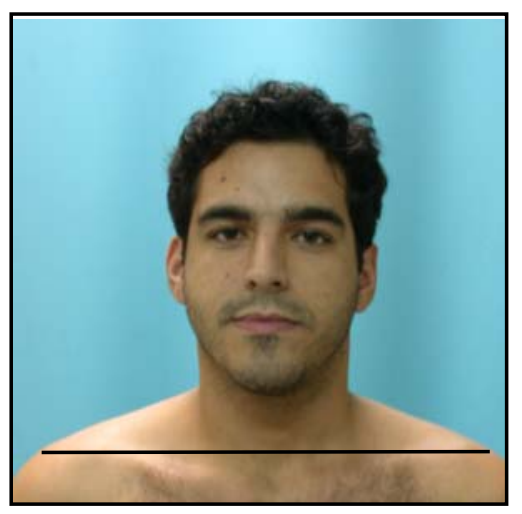

Figura 11. Avaliação da altura dos ombros. 


\subsection{Critério para análise dos dados}

Quanto à postura de cabeça, foram considerados como normalidade e alteração para:

1- Linha Bipupilar

normalidade: horizontalizada ( $0^{\circ}$ - paralela ao solo)

alteração: inclinada à $\mathrm{D}$ ou $\mathrm{E}$

2- Cabeça face anterior

normalidade: perpendicular ao solo $\left(90^{\circ}\right)$

alteração: inclinação lateral (D ou E) e/ou rotação (D ou E)

3- Cabeça face lateral

normalidade: centralizada

alteração: flexão ou protrusão

4- Coluna cervical

normalidade: Iordose fisiológica

alteração: aumento da lordose fisiológica

5- Tonicidade

normalidade: 0 (normotonia)

alteração: +1 , quando havia hipertonia leve (tônus levemente aumentado), +2, quando havia hipertonia (tônus aumentado), -1 , na presença de hipotonia leve (pouca diminuição do tônus) e -2, quando havia hipotonia (tônus diminuído). Tais parâmetros para graduação de tonicidade são os mesmos descritos por Tome et al (2003). 
6- Mobilidade ativa da cabeça

* Flexão e extensão

normalidade: flexão - permite encostar o mento na face anterior do tórax (Hoppenfeld 1999), 0 -65 (Marques 1997)

extensão - a cabeça deve mover-se posteriormente, permitindo a visão do teto acima da mesma (Hoppenfeld 1999), 0-50 (Marques 1997)

alteração: limitação dos movimentos

* Rotação lateral da cabeça

normalidade: permite que 0 mento quase se alinhe com 0 ombro (Hoppenfeld 1999), 0-45 (Marques 1997)

alteração: limitação do movimento

* Inclinação lateral da cabeça

normalidade: permite pender a cabeça lateralmente, $0-40^{\circ}$ (Marques 1997)

alteração: limitação do movimento

7- Sintomatologia dolorosa

normalidade: ausência de dor

alteração: presença de dor

8- Altura dos ombros

normalidade: horizontalizados $\left(0^{\circ}\right.$ - paralelos ao solo)

alteração: elevado à $\mathrm{D}$ ou à $\mathrm{E}$ 
As informações obtidas foram comparadas em relação às avaliações realizadas nas fases pré e pós-cirúrgica, classificando-se como:

- adequou, quando o aspecto avaliado encontrava-se alterado na fase pré-cirúrgica, tornando-se adequado após a mesma;

- permaneceu alterado, quando já havia alteração antes da cirurgia e a mesma não foi corrigida após a cirurgia;

- permaneceu normal, quando o padrão de normalidade pré-cirúrgico não sofreu alteração após a cirurgia;

- piorou, quando o padrão de normalidade pré-cirúrgico tornou-se alterado após a cirurgia.

Os resultados foram descritos utilizando processos de estatísticas descritivas (tabelas e gráficos). 
Resultados 


\section{RESULTADOS}

A seguir, serão apresentados os resultados referentes aos 6 indivíduos avaliados, comparando-se as informações obtidas nas duas avaliações realizadas.

Quanto à saúde geral, pode ser notado presença de algum tipo de queixa para $1 / 3$ dos casos, tanto na fase pré-cirúrgica quanto na fase póscirúrgica (figura 12). Dentre as queixas apresentadas, destaca-se enxaqueca, relatada por 1 caso nas duas fases (indivíduo 6), além de dor e desconforto na região da ATM e trapézio (indivíduo 4), relatada por 1 indivíduo nas duas fases.

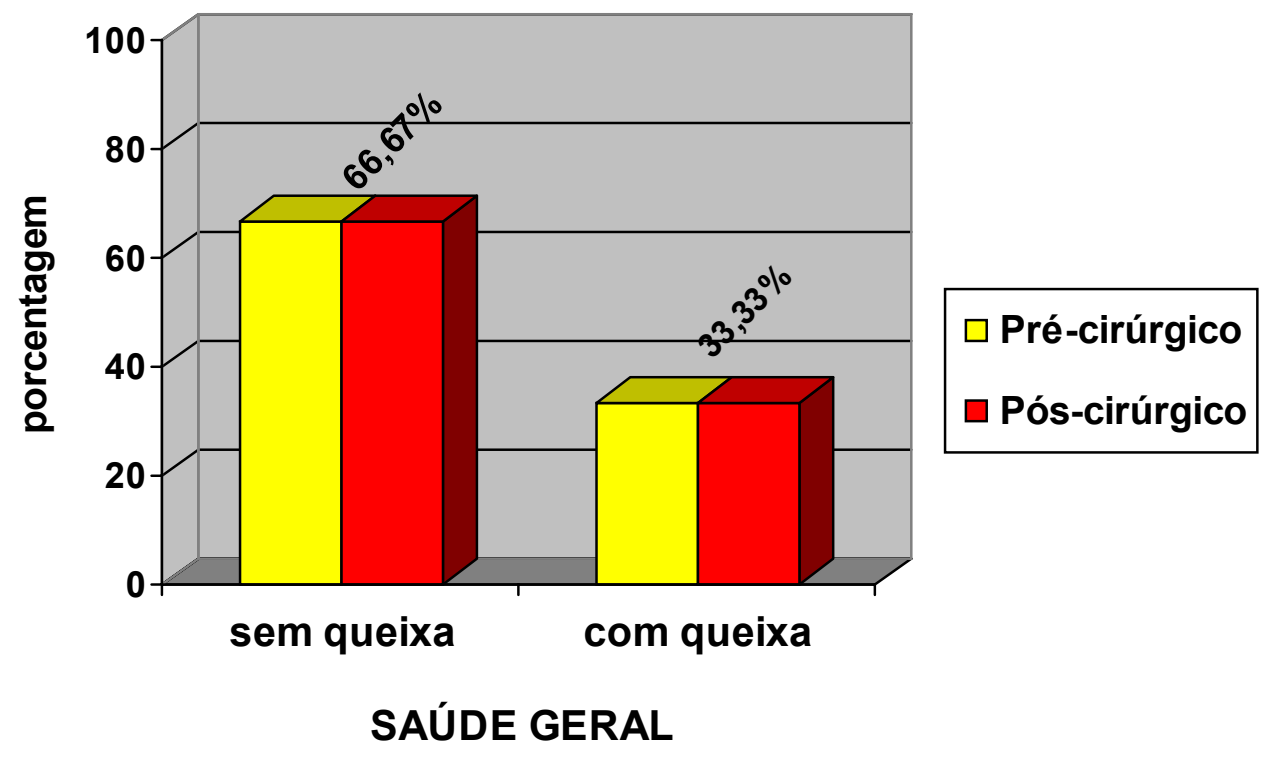

Figura 12. Porcentagem de indivíduos de acordo com a presença ou ausência de alteração na saúde geral. 
Quanto à postura da cabeça, verificou-se a linha bipupilar, a face anterior e a face lateral. Em relação à linha bipupilar, nota-se na figura 13 que metade dos indivíduos permaneceram com o padrão alterado após a cirurgia, enquanto 1/3 permaneceu normal e 1 caso apresentou adequação.

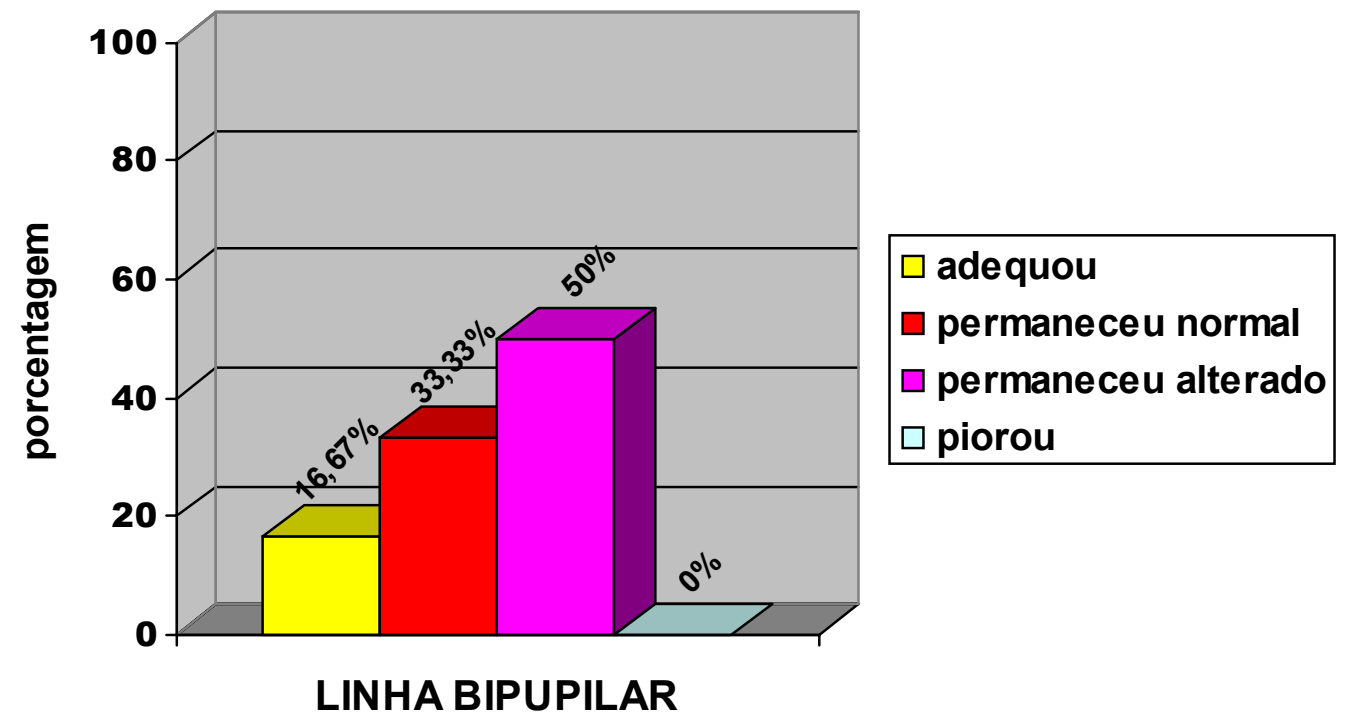

Figura 13. Porcentagem de indivíduos de acordo com a altura da linha pupilar. 
Em relação à cabeça face anterior, nota-se na figura 14 que 1 indivíduo $(16,67 \%)$ que apresentava alteração na fase pré-cirúrgica passou a apresentar a posição correta da cabeça após a cirurgia (centralizada); 2/3 dos indivíduos permaneceram com alteração, enquanto 1 indivíduo apresentou piora.

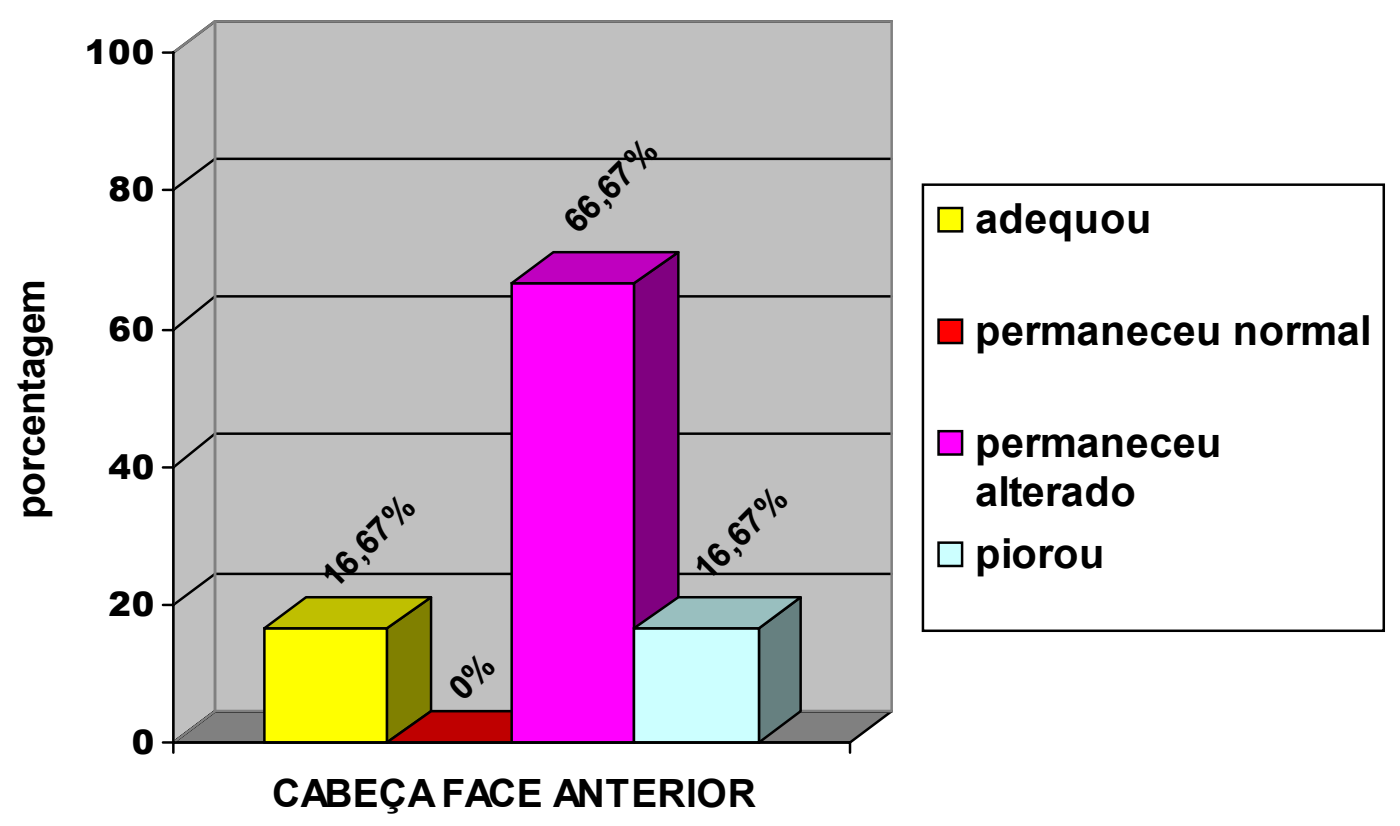

Figura 14. Porcentagem de indivíduos de acordo com a posição da cabeça face anterior. 
Em relação à cabeça face lateral, nota-se na figura 15 que $2 / 3$ dos indivíduos permaneceram com o padrão de normalidade (cabeça centralizada), 1 indivíduo (1/6) permaneceu com alteração enquanto o outro obteve adequação, não havendo casos de piora quanto a esse aspecto.

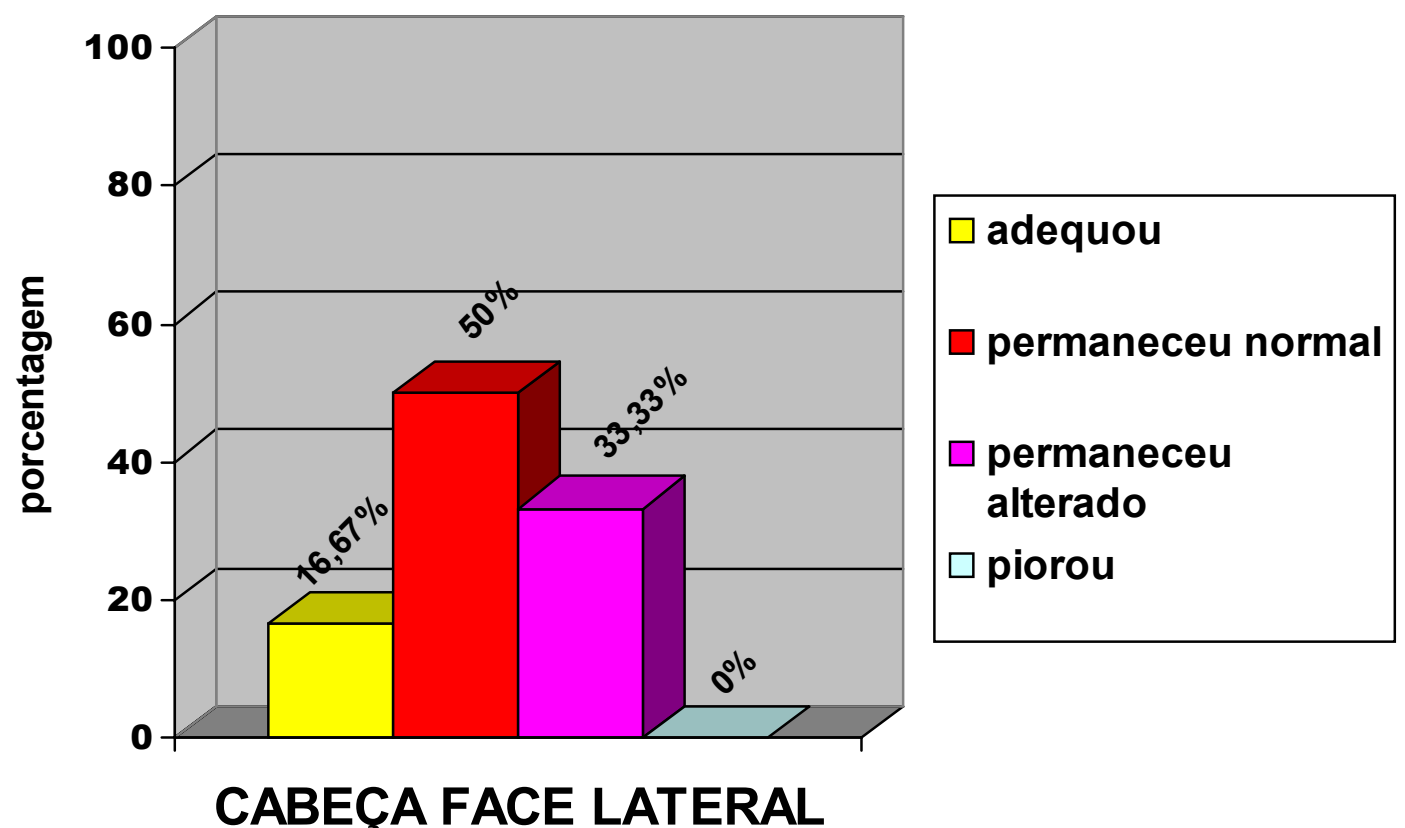

Figura 15. Porcentagem de indivíduos de acordo com a posição da cabeça face lateral. 
Quanto à coluna cervical, verificou-se o perfil desta, notando-se na figura 16 que metade da amostra permaneceram com lordose fisiológica (normalidade), 1/3 permaneceram com o padrão alterado, e 1 (1/6) apresentou adequação da alteração pré-cirúrgica, não sendo observados casos de piora também para esse aspecto.

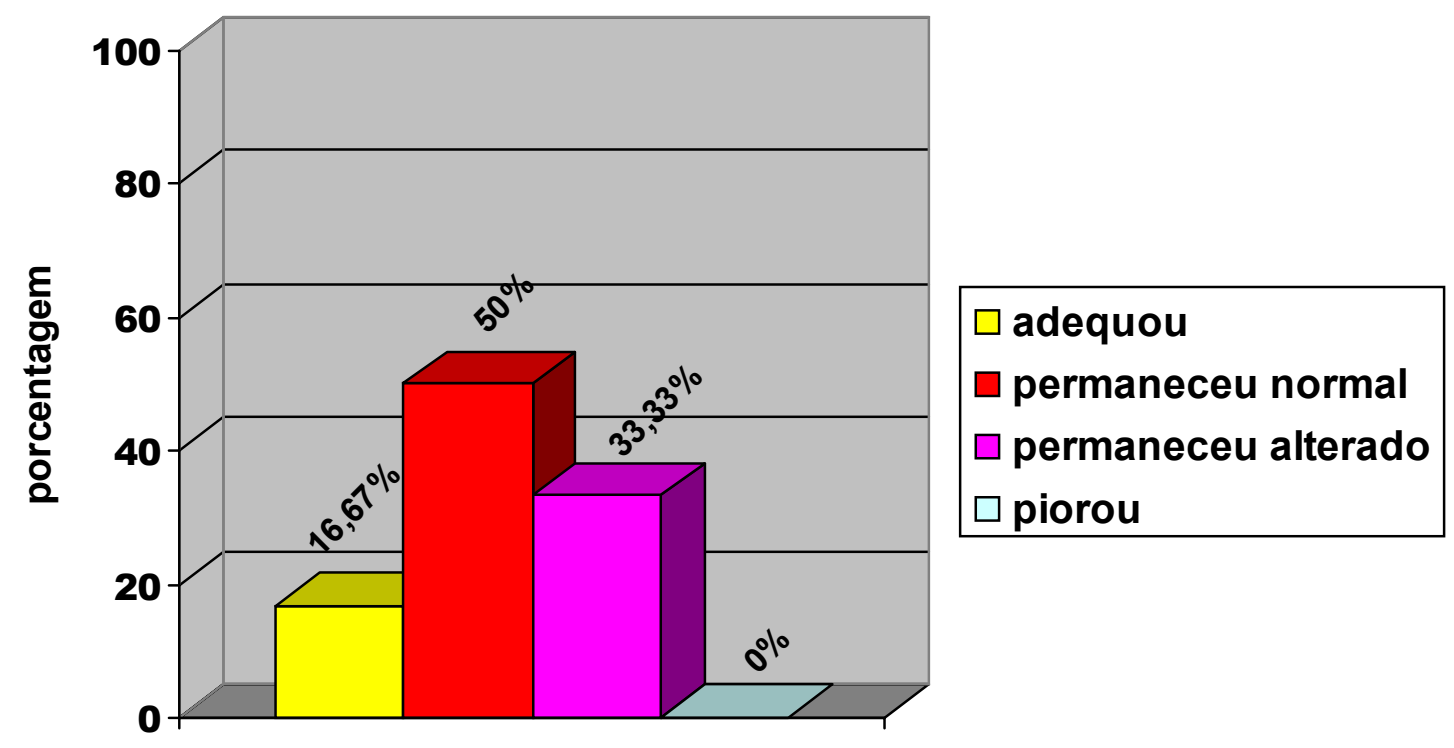

COLUNA CERVICAL

Figura 16. Porcentagem de indivíduos de acordo com o perfil da coluna cervical. 
Quanto à condição muscular das regiões da face e cervical, foi avaliada a tonicidade dos músculos masseteres, trapézios e esternocleidomastóideos. No que se refere aos músculos masseteres, pode ser observado, na figura 17 , que os indivíduos 1 e 3 apresentavam normotonia no pré-cirúrgico e permaneceram da mesma forma no pós-cirúrgico, enquanto os indivíduos 2 e 6 apresentavam hipotonia leve e continuaram com o mesmo padrão após a cirurgia. Já os indivíduos 4 e 5 a apresentavam hipotonia leve passaram a hipotonia.

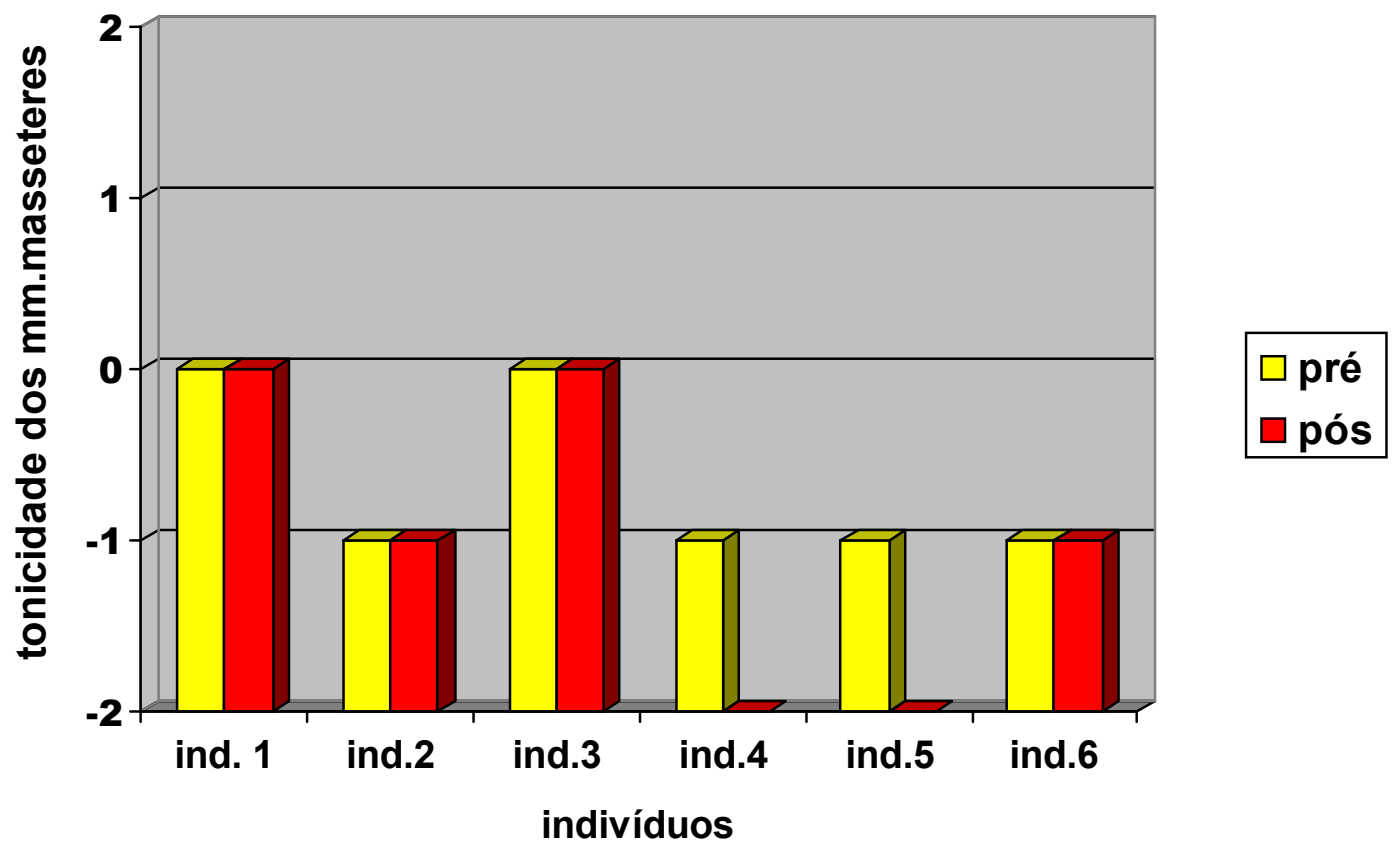

Figura 17. Porcentagem de indivíduos de acordo com a tonicidade dos músculos masseteres. 
No que se refere aos músculos esternocleidomastoideos, pode ser observado, na figura 18, que os indivíduos 2, 45 e 6, permaneceram com normotonia após a cirurgia (4 de 6 indivíduos), enquanto o indivíduo 1 apresentou hipertonia leve e após a cirurgia normotonia e o indivíduo 3, que apresentava hipotonia leve passou a apresentar normotonia. Pode ser observado, portanto, que, na fase pós-cirúrgica, todos estavam dentro do padrão de normalidade.

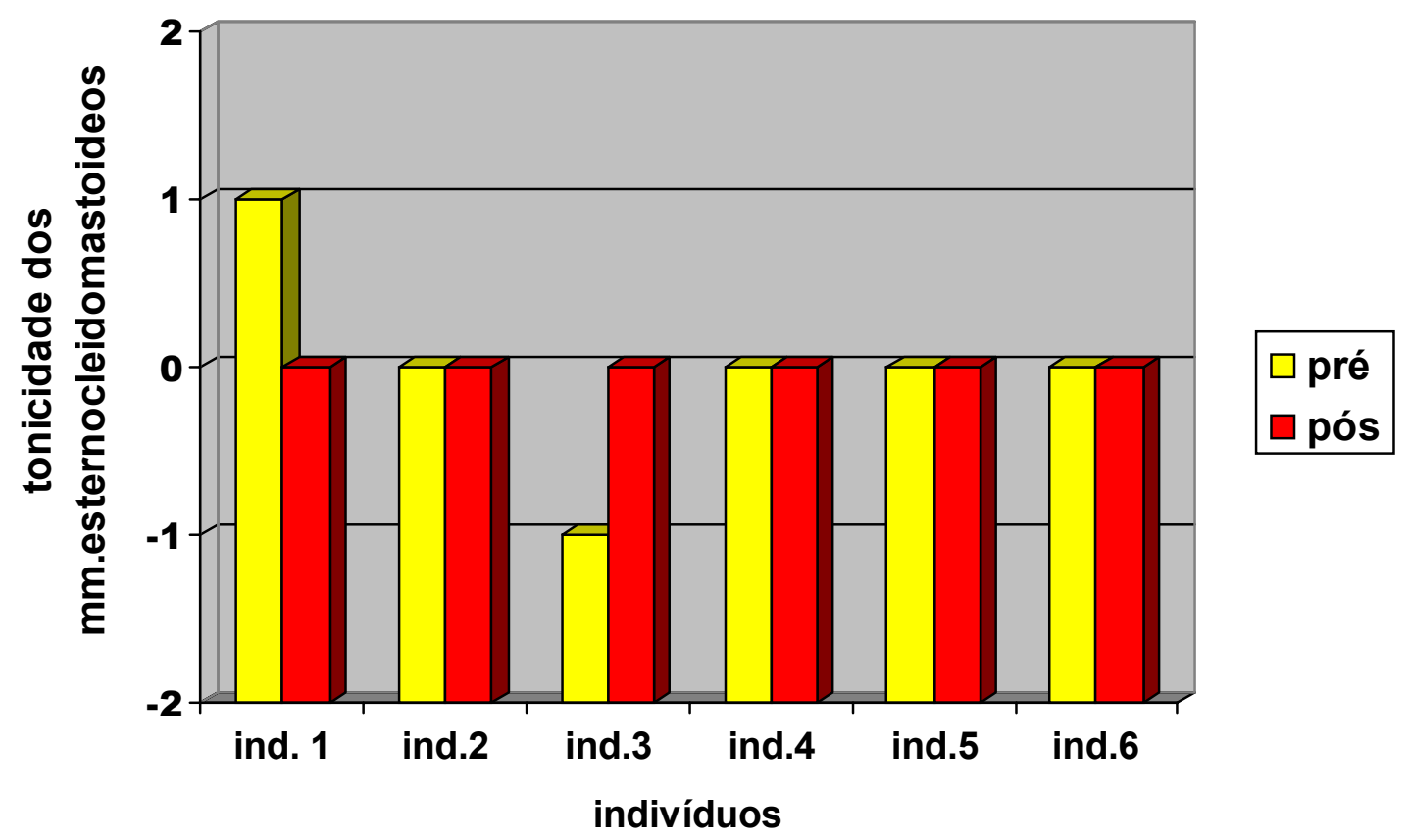

Figura 18. Porcentagem de indivíduos de acordo com a tonicidade dos músculos esternocleidomastóideos. 
No que se refere aos músculos trapézio, pode ser observado, na figura 19, que todos os indivíduos apresentavam hipertonia leve no lado direito, o que permaneceu após a cirurgia, enquanto o trapézio esquerdo apresentou-se normotônico, tanto antes quanto após a cirurgia, nos indivíduos 1, 25 e 6 (4 de 6 indivíduos). Também do lado esquerdo, o músculo trapézio do indivíduo 3 passou de hipertonia para hipertonia leve e o 4 permaneceu com hipertonia.

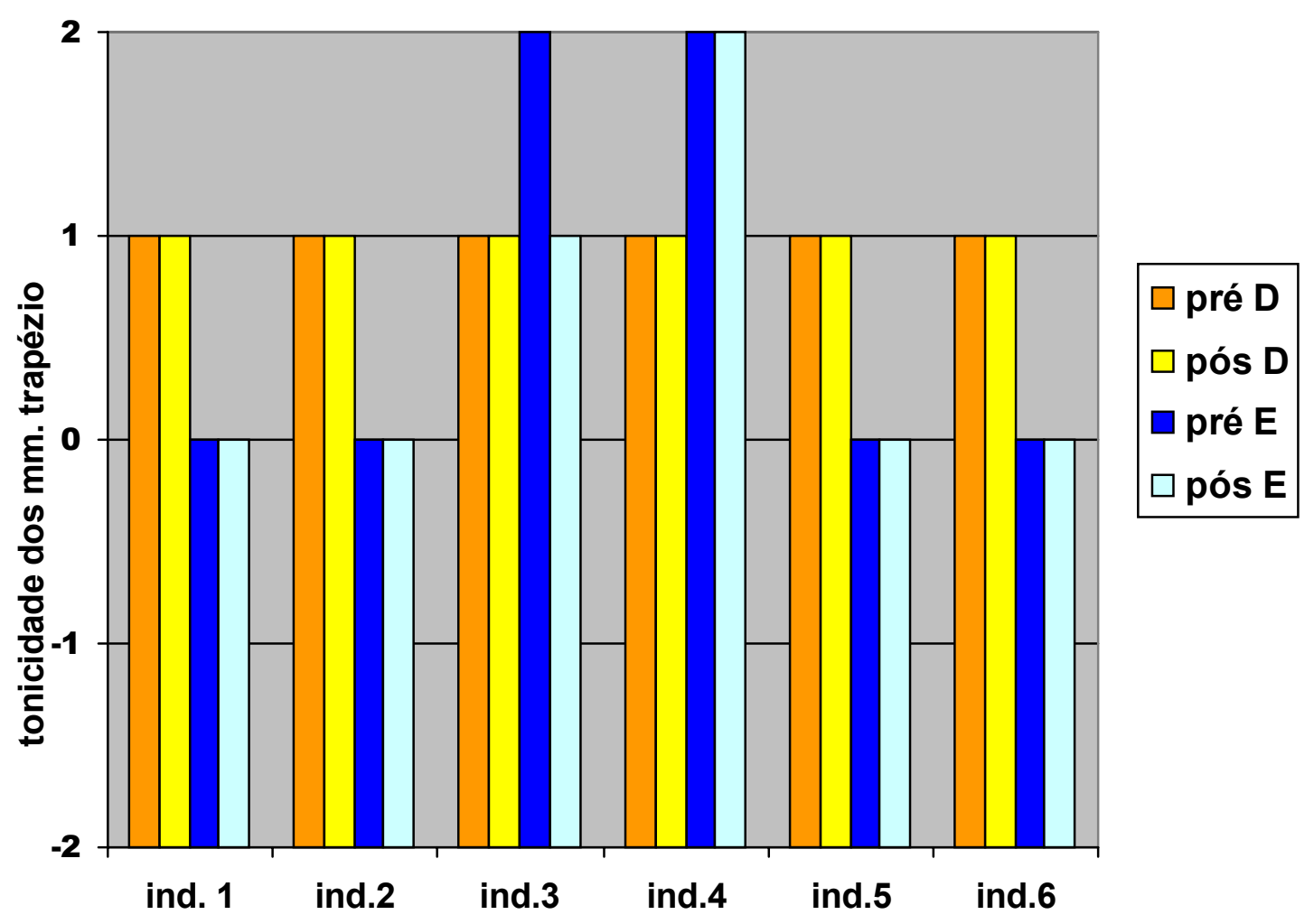

Figura 19. Porcentagem de indivíduos de acordo com a tonicidade dos músculos trapézios. 
A mobilidade ativa da cabeça foi avaliada quanto aos movimentos de flexão, extensão, rotação e inclinação lateral. Na flexão e na extensão de cabeça, nota-se, na figura 20 , que todos os indivíduos não apresentaram limitação, mantendo a normalidade após a cirurgia ortognática.

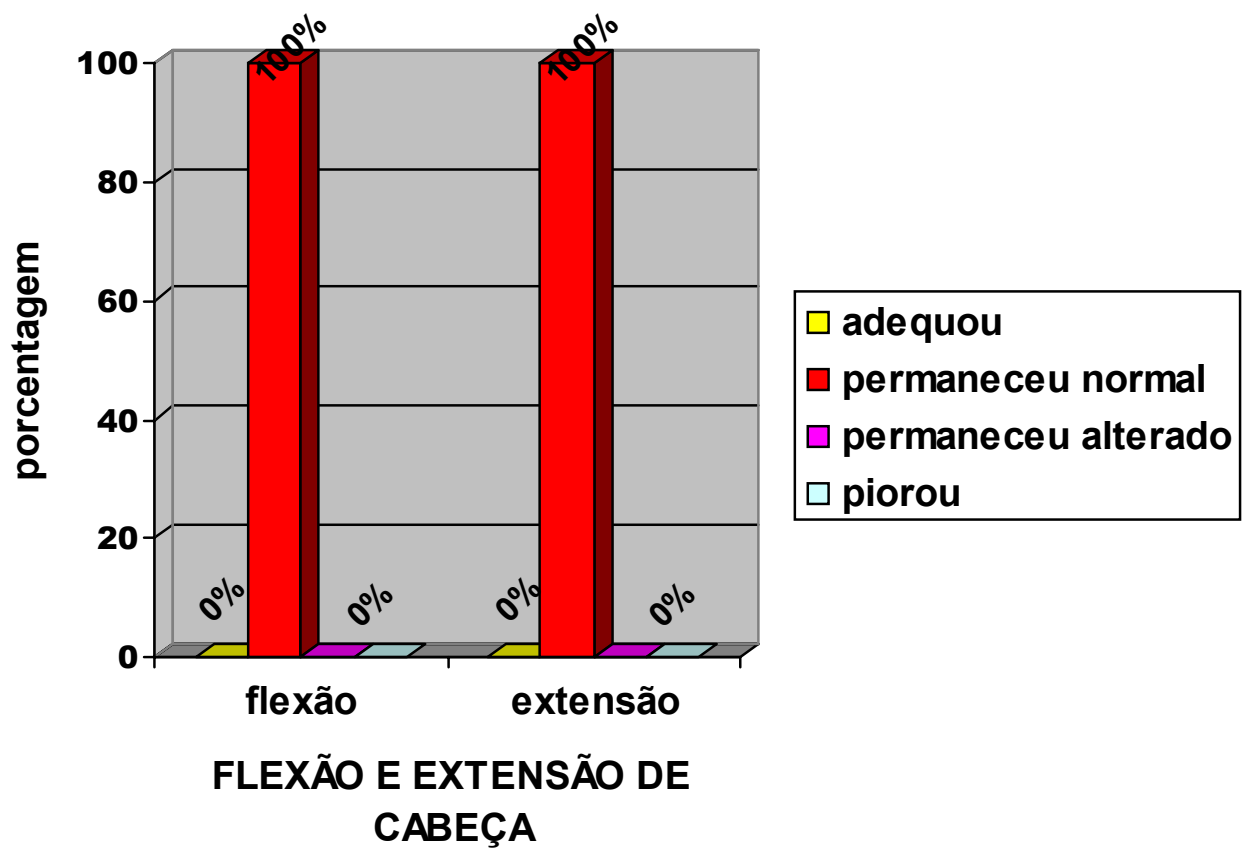

Figura 20. Porcentagem de indivíduos de acordo com os resultados de flexão e extensão de cabeça. 
Na rotação de cabeça, nota-se, na figura 21, que a maioria dos sujeitos (4/6) permaneceram com o padrão de normalidade pré-cirúrgico. No lado direito, 2 indivíduos passaram a apresentar limitação do movimento após a cirurgia; no lado esquerdo, 1 adequou o padrão e o outro permaneceu com limitação.

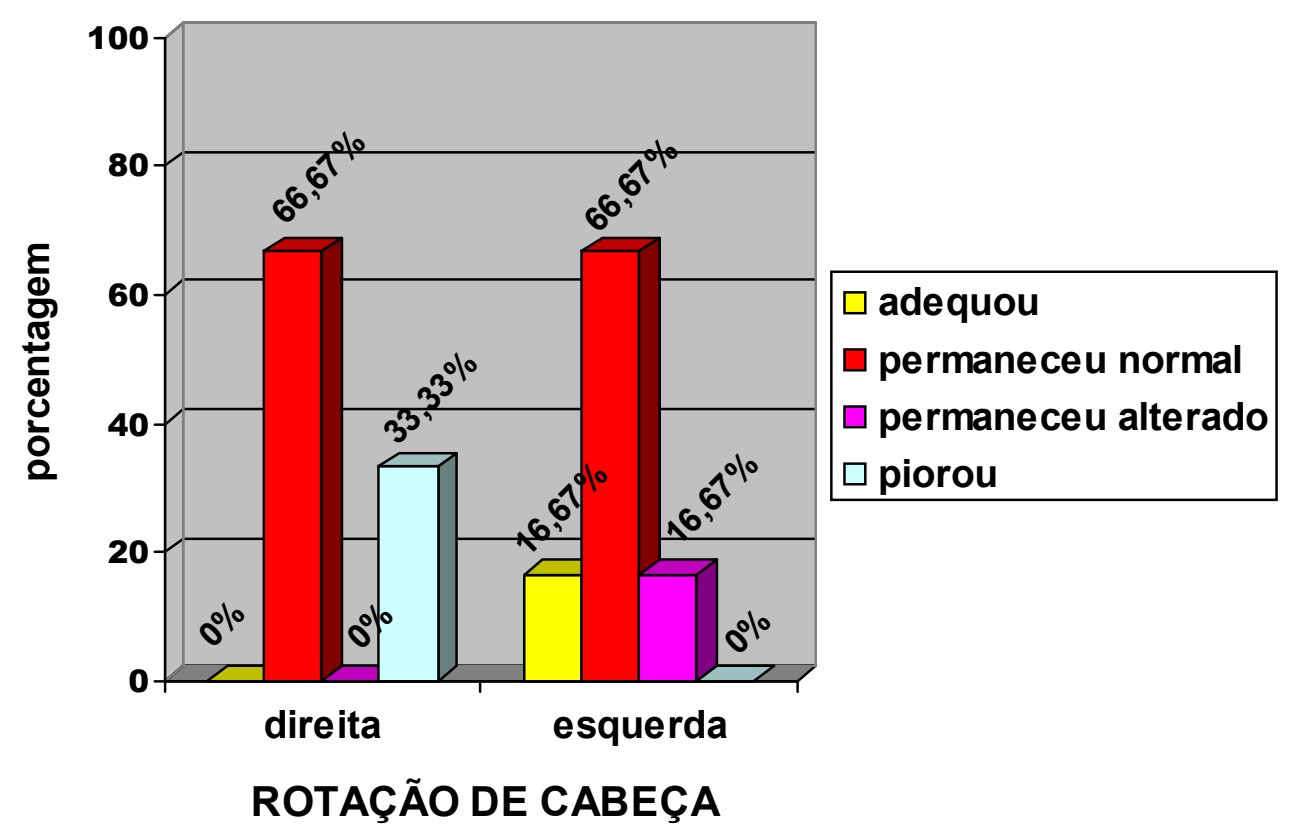

Figura 21. Porcentagem de indivíduos de acordo com a rotação de cabeça. 
$\mathrm{Na}$ inclinação lateral da cabeça (figura 22), o resultado mais encontrado foi a permanência do padrão de normalidade, sendo em $2 / 3$ dos indivíduos no lado direito e metade dos mesmos no lado esquerdo. No lado direito, os outros 2 indivíduos passaram a apresentar limitação do movimento, enquanto no lado esquerdo os outros 3 indivíduos distribuíram-se nos resultados de adequação, permanência com alteração e piora.

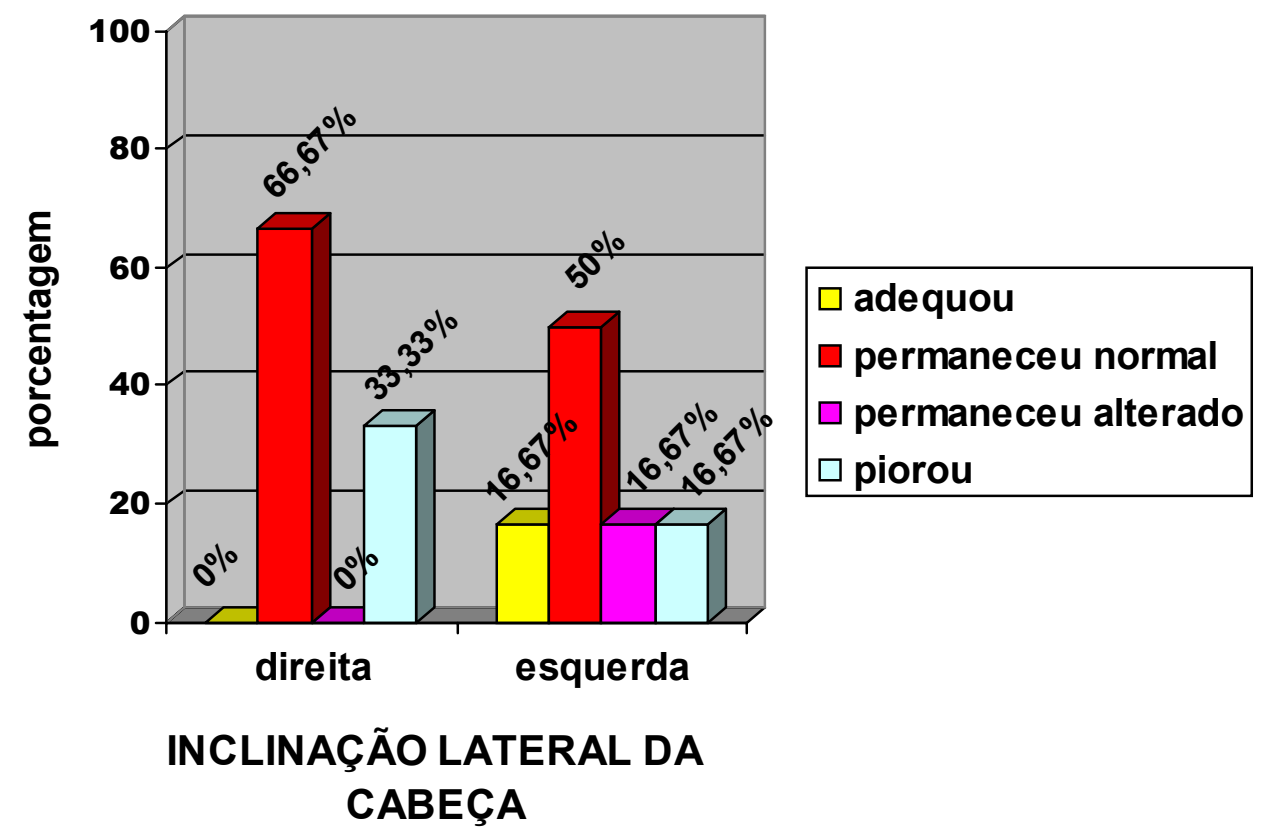

Figura 22. Porcentagem de indivíduos de acordo com a inclinação lateral da cabeça. 
Com relação à sintomatologia dolorosa, foi analisado o relato de dor nos músculos trapézio, esternocleidomastóideo e na ATM, conforme relatado pelos indivíduos. Na figura 23, observa-se o resultado quanto à dor à palpação nos músculos trapézios (direito e esquerdo), em que, no lado direito, houve um equilíbrio entre os casos que apresentavam dor antes da cirurgia e após a mesma não mais apresentaram, permanência sem dor e permanência com dor. Já no lado esquerdo, predominou a permanência com dor em metade dos sujeitos. Em ambos os lados não houve queixa de dor apenas após a cirurgia.

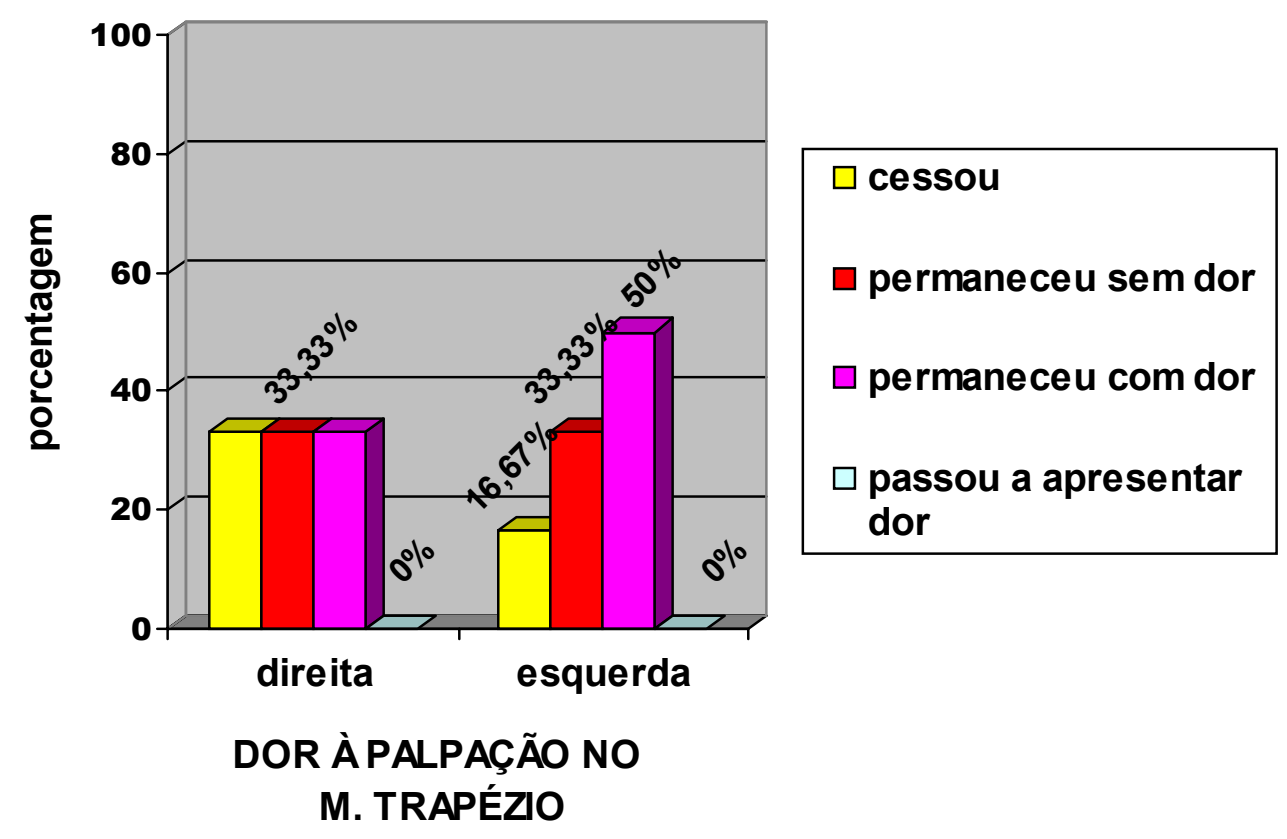

Figura 23. Porcentagem de indivíduos de acordo com a presença de dor à palpação nos músculos trapézios. 
$\mathrm{Na}$ figura 24, observa-se a dor à palpação nos músculos esternocleidomastóideos (direito e esquerdo), em que ambos os lados apresentaram o mesmo resultado, permanecendo a maioria sem dor, enquanto 1 indivíduo passou a apresentar dor após a cirurgia e outro não referiu mais dor após a mesma.

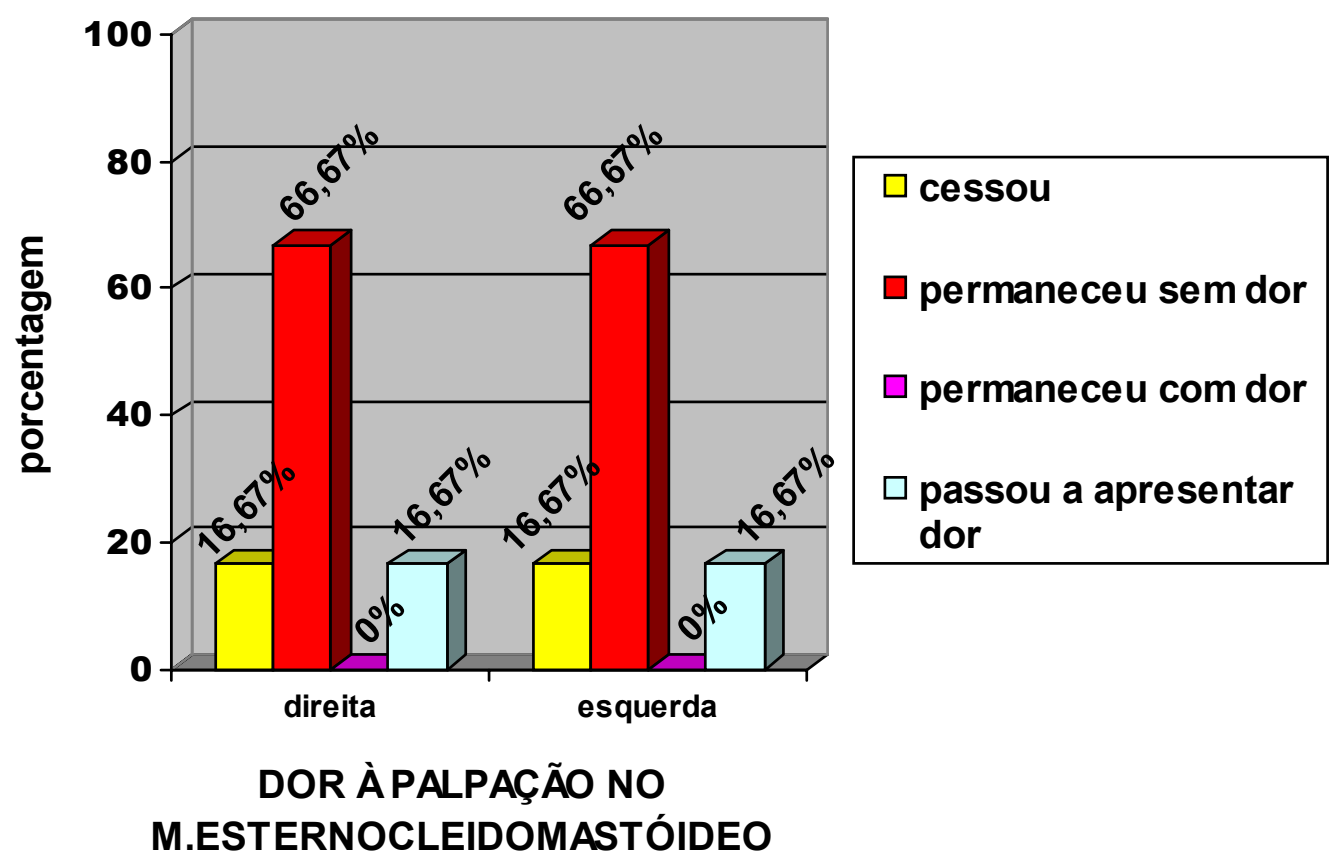

Figura 24. Porcentagem de indivíduos de acordo com a presença de dor à palpação nos músculos trapézios. 
Na figura 25, observa-se a dor à palpação na ATM (direita e esquerda), 1 indivíduo deixou de referir dor após a cirurgia, sendo essa presente na fase pré-cirúrgica apenas no lado direito. Os demais não apresentaram dor à palpação nessa região em nenhuma das fases.

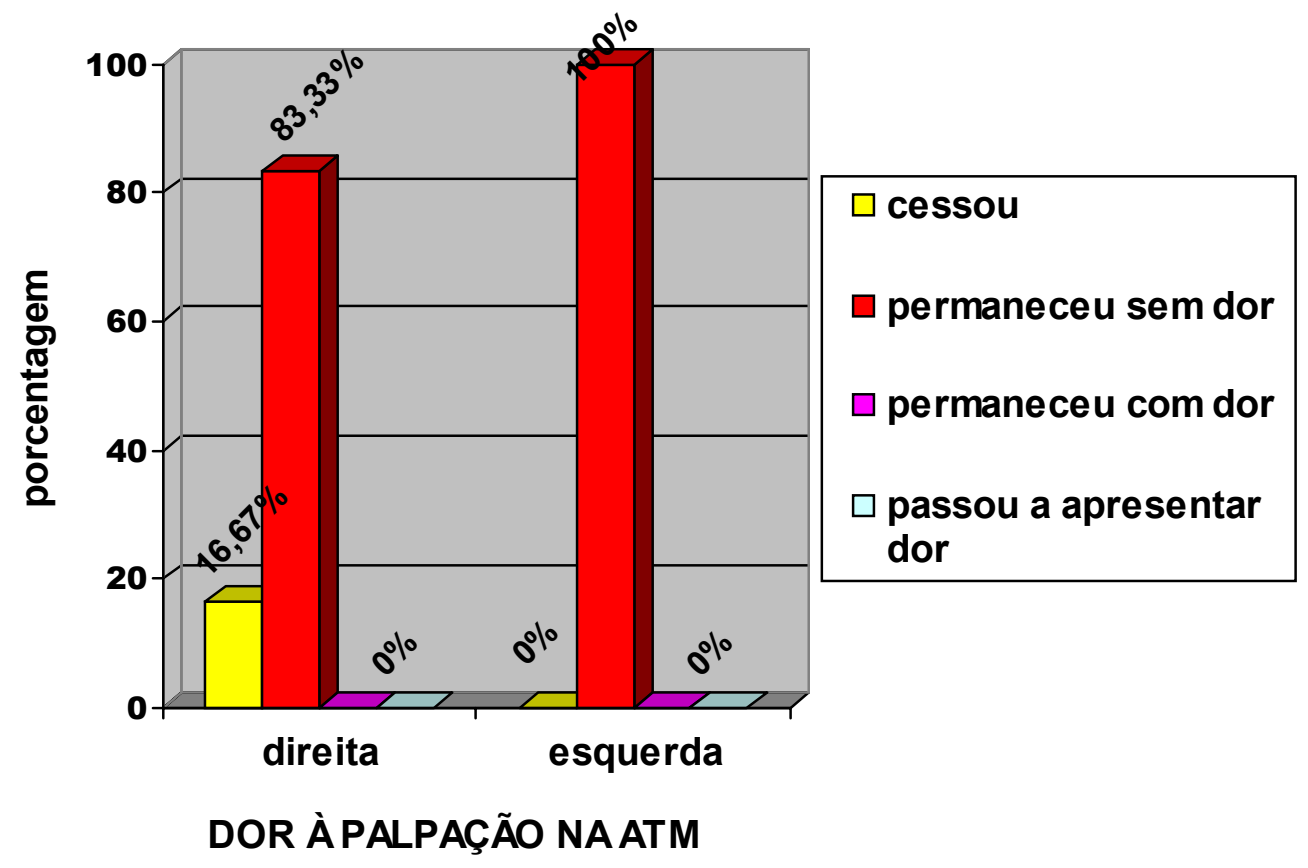

Figura 25. Porcentagem de indivíduos de acordo com a presença de dor à palpação nas ATMs. 
Quanto à altura dos ombros, na figura 26, observa-se que, no lado direito, dois terços dos indivíduos apresentavam alteração pré-cirúrgica e permaneceram da mesma forma após a cirurgia. Já no lado esquerdo, metade dos indivíduos permaneceram com o padrão de normalidade, 1 adequou após a cirurgia, e 2 permaneceram com alteração.

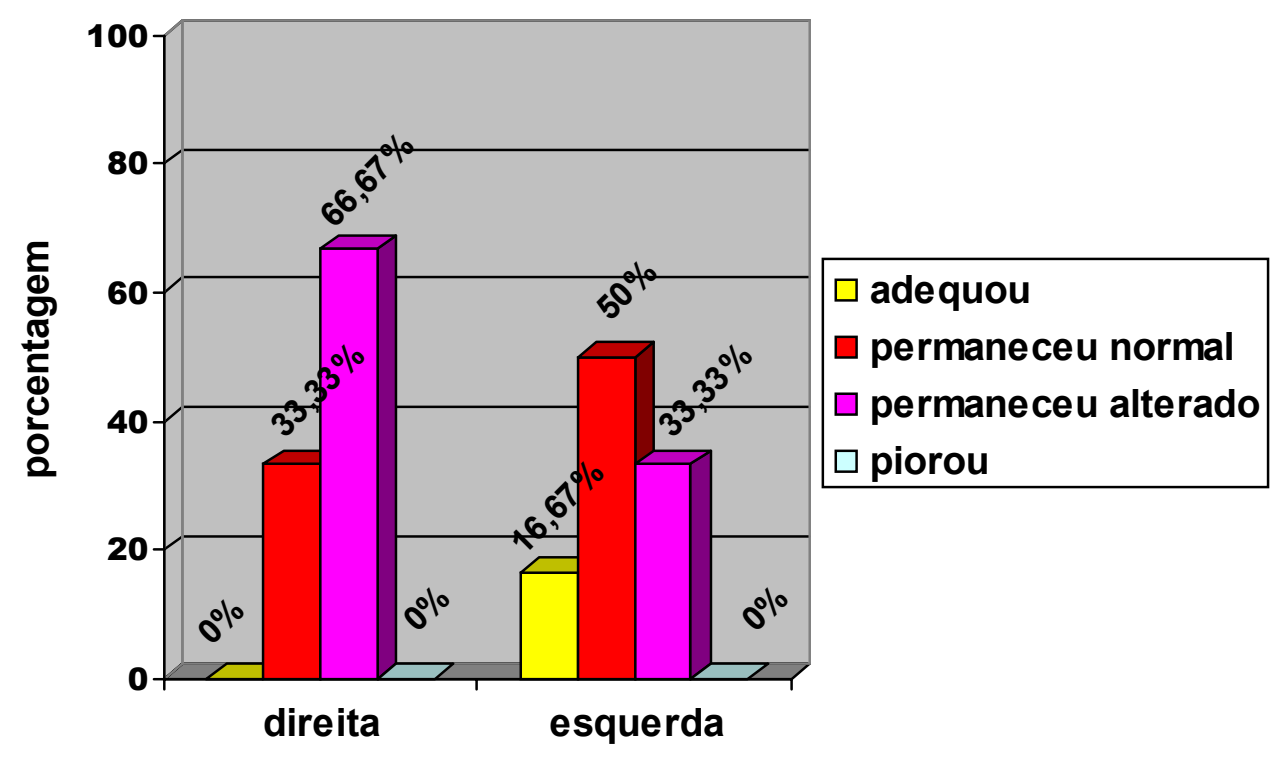

ALTURA DOS OMBROS

Figura 26. Porcentagem de indivíduos de acordo com a altura dos ombros. 
Discussão 


\section{DISCUSSÃO}

O corpo humano é uma unidade sincrônica e indissociável e a postura adequada da cabeça e da coluna vertebral cervical é importante para a funcionalidade do sistema estomatognático (Goldstein et al 1984), sendo, da mesma forma, importante a integridade anátomo-funcional desse sistema para a manutenção e a postura adequada da cabeça e coluna cervical (Rocabado 1979, Berretin-Felix et al 2004).

Além das alterações respiratórias (Vig et al 1980, Hruska 1997 e Krakauer 1997), as má oclusões são alterações do sistema estomatognático que podem influenciar na postura da cabeça e coluna cervical (MacConkey 1991, Solow e Sonnesen 1998, Bricot 1999 e Tessitori 2004). Quando essas más oclusões envolvem o terço médio da face, são denominadas deformidades dentofaciais, comuns em indivíduos com fissura labiopalatina reparada, que muitas vezes apresentam mordida cruzada total, envolvendo alterações nos sentidos anteroposterior e transversal. Para a correção dessas deformidades, em muitos casos é necessária a cirurgia ortognática, podendo-se utilizar o avanço de maxila, que foi o procedimento realizado nos indivíduos avaliados no presente estudo.

$\mathrm{Na}$ literatura, podem ser encontrados poucos trabalhos que relacionam as modificações estruturais decorrentes da cirurgia ortognática à postura de cabeça (Phillips et al 1991 e Benech et al 1997), o que, além da importância, justifica o propósito do tema do presente trabalho.

Para atingir o objetivo, as avaliações foram realizadas, mantendo o indivíduo o mais próximo de sua postura usual de cabeça, uma vez que se solicitássemos algum padrão como olhar para um ponto fixo ou "posição natural da cabeça", perderíamos a espontaneidade da postura. Hoppenfeld (1999) descreve a inspeção por meio da observação visual desde o momento da entrada do indivíduo na sala de avaliação até seus movimentos ao despir a blusa, para constatar limitações de movimentos ou alterações da cabeça e coluna cervical. A observação visual, também utilizada no presente estudo, facilita ao paciente manter-se com o mínimo nível de estresse e o mais natural possível, pois as solicitações são simples de serem executadas. Outros autores 
(Athanasiou et al 1991, Schellino et al 1991 e Samman et al 2002) utilizam exames complementares como raio $X$ para análise cefalométrica, que seria um procedimento a mais, que exporia o indivíduo à radiação e não avaliaria a espontaneidade da postura usual. A única limitação da forma de análise utilizada seria a falta de dados mensuráveis, porém, outras medidas poderiam também comprometer a espontaneidade.

Além dessa análise, foram obtidos dados de anamnese no que se refere à saúde geral, sendo que, como observado na figura 12, 2 indivíduos relataram dores. A enxaqueca pode ou não estar relacionada à alteração da postura de cabeça, presente no indivíduo avaliado (número 6), uma vez que a enxaqueca é uma doença cujas causas são variadas (Peterlin e Ward 2005). Já o indivíduo número 4, relatou dor na região da ATM e trapézio, o que pode estar relacionado com a alteração postural apresentada por esse indivíduo. A relação entre postura de cabeça e dor nessas regiões está relatado na literatura (Gelb 1994 e Lima et al 2004). Porém, Fuentes et al (1999) não encontraram relação entre dor na região da ATM e alteração postural. A cirurgia ortognática, no presente estudo, não teve influência sobre essas queixas. Já no estudo de Benech et al (1997), foi estudada a presença de cefaléia e encontrado que no pré-operatório a porcentagem era de $65 \%$ dos pacientes, enquanto no pós $35 \%$ dos pacientes. Quanto às dores relacionadas à região cervical, estavam presentes em $60 \%$ dos pacientes antes e, no pós-cirúrgico $27 \%$ dos pacientes. Além disso, dor articular, no mesmo estudo, foi encontrada em $40 \%$ no pré e $20 \%$ da população estudada.

Não foram encontradas outras alterações de saúde, inclusive problemas de coluna, dores nas costas e no pescoço, mesmo nos outros indivíduos com alteração postural, que poderia estar relacionada a essas queixas (Kinser e Colby 1989). De qualquer forma, a cirurgia ortognática não teve influência sobre a saúde geral. Na literatura, encontra-se resultados de melhora na qualidade da saúde geral após a cirurgia (Motegi et al 2003). Deve ser considerado que a avaliação no presente estudo foi realizada de 3 a 6 meses após a cirurgia, enquanto e os resultados no trabalho citado foram avaliados com 2 a 5 anos de pós-cirúrgico. Dessa forma, a melhora na saúde geral deve ser progressiva, conforme relatado por Hatch et al (1998), após avaliar esse 
aspecto em vários tempos de pós-cirúrgico (1 semana, 8 semanas, 6 meses, 1 ano e 2 anos após a cirurgia).

Na figura 13, pode ser observado que a cirurgia ortognática influenciou a linha bipupilar em apenas 1 caso, que passou a apresentá-la horizontalizada após a cirurgia, o que pode inferir uma adequação da postura da cabeça. Não foi encontrado relatos na literatura relacionando linha bipupilar e cirurgia ortognática. Porém, a linha bipupilar horizontalizada indica a posição correta da cabeça (Bricot 1999).

Com relação à cabeça face anterior (figura 14), observou-se que a cirurgia teve influência positiva em 1 caso e negativa em outro, não influenciando os demais casos, que permaneceram com alteração. A maioria (5/6) dos indivíduos apresentava alteração desse aspecto. Porém, após a correção dessa deformidade, apenas 1 caso adequou e outro ainda passou a apresentar alteração após a cirurgia, demonstrando que esse aspecto pode estar relacionado a outros fatores além das más oclusões (Hoppenfeld 1999), sendo comum encontrar alteração da cabeça face anterior na população em geral, na inspeção visual (Hoppenfeld 1999).

Já referente à cabeça face lateral (figura 15), encontramos um menor índice de alterações antes e após a cirurgia, sendo que a cirurgia levou à adequação desse aspecto em 1 indivíduo, permanecendo os demais da mesma forma (4 normal e 1 alterado). Phillips et al (1991) não encontraram diferenças significantes entre as avaliações pré e pós-cirúrgica com relação a esse aspecto. Apesar de deformidades dentofaciais estarem relacionadas, em muitos casos, à respiração oral, inclusive em indivíduos com fissura labiopalatina (Precious et al 2001), e a respiração oral relacionada a uma alteração postural, geralmente protrusão de cabeça (Krakauer 1997 e Tessitore 2004), isso não foi observado na maioria dos indivíduos do presente estudo, exceto o que apresentou adequação, uma vez que a correção da deformidade pode levar a uma melhora da respiração (Trindade et al 2003). A respiração oral não foi investigada, o que deve ser abordado em estudos futuros.

Com relação aos resultados da coluna cervical (figura 16), os resultados foram variados, sendo que a lordose fisiológica refere-se à normalidade e foi encontrada em metade dos indivíduos antes da cirurgia e 2/3 após a cirurgia, 
havendo a adequação em 1 indivíduo. Phillips et al (1991) mediram, por meio de cefalogramas, a lordose, não encontrando diferença entre os períodos pré e pós-cirúrgico com relação a esse aspecto.

A condição muscular das regiões da face e cervical, foi avaliada por meio da verificação da tonicidade dos músculos masseteres, trapézios e esternocleidomastóideos. Com relação aos masseteres (figura 17), foi observado que a cirurgia ortognática apresentou influência em dois indivíduos, refletindo em piora da tonicidade, o que pode ser explicado pelo período em que a musculatura permanece em repouso, quando o indivíduo é impedido de realizar a mastigação (van den Braben et al 2004). Essa redução da atividade da musculatura no repouso após a cirurgia ortognática foi confirmada por Raberin (2000).

Com relação à tonicidade dos músculos esternocleidomastoideos (figura 18), foi observada a normalidade pré-cirúrgica da maioria, e pós-cirúrgica da totalidade. O esternocliedomastoideo é um flexor e rotador primário (Hoppenfeld 1999), devendo esse aspecto ser melhor observado em estudos futuros, com um número maior de indivíduos.

Os músculos trapézios (figura 19) apresentaram-se hipertônicos do lado direito antes e após a cirurgia. Já do lado esquerdo, isso foi observado em apenas 2 indivíduos, apresentando melhora em 1 desses. Uma possível explicação para a hipertonia predominante do lado direito seria a dominância lateral, como relatado por Farina et al (2003), que justifica afirmando que o uso preferencial de um lado por um período prolongado leva a mudanças na membrana das fibras musculares e nas propriedades de controle. Uma outra justificativa seria de uma existência antálgica antecipatória, visando inconscientemente, eliminar experiência de dor pré-existente.

A mobilidade ativa da cabeça foi avaliada quanto aos movimentos de flexão, extensão, rotação e inclinação lateral. Tanto a flexão quanto a extensão (figura 20) apresentaram-se dentro dos limites de normalidade para todos os sujeitos em ambas as fases do tratamento, sugerindo que a cirurgia ortognática não restringiu esses movimentos nos indivíduos avaliados, independente da técnica utilizada. Wenzel et al (1989) encontrou que a cirurgia para correção de prognatismo mandibular pode resultar em extensão persistente da cabeça. 
Porém, em apenas um indivíduo avaliado essa técnica foi utilizada em associação com o avanço da maxila, obtendo os mesmos resultados dos demais indivíduos. Já quanto à rotação e inclinação lateral da cabeça (figuras 21 e 22), foi observado um padrão de normalidade.

Quanto à dor à palpação nos músculos trapézios (figura 23), houve equilíbrio entre os resultados do lado direito e maior índice de dor do lado esquerdo, podendo este dado estar relacionado à postura prolongada, devido à preferência da dominância. Os indivíduos que apresentaram hipertonicidade, a qual pode estar relacionada com a dominância, conforme relatado, provavelmente apresentariam menos queixa de dor, uma vez que aquele é o seu padrão habitual.

Já quanto à dor nos músculos esternocleidomastóideos (figura 24), pode também estar relacionada à postura inadequada prolongada. Na literatura, não foi encontrado nenhum relato sobre a relação entre cirurgia ortognática e atividade ou dor nos músculos esternocleidomastóideos, apenas sobre a relação entre a cirurgia e dor à palpação na ATM. Benech et al (1997) encontraram presença em $40 \%$ no pré e $13 \%$ no pós-cirúrgico, havendo portanto uma redução. No presente estudo, o único indivíduo que apresentou dor antes da cirurgia deixou de referí-la no pós-operatório (figura 25). Isso confirma que a normalização da oclusão pode diminuir a sintomatologia dolorosa na ATM (Panula et al 2000 e Pahkala e Heino 2004).

Por fim, a altura dos ombros (figura 26) apresentou-se alterada na maioria dos indivíduos do lado direito, enquanto a metade do lado esquerdo apresentou-se dentro do padrão de normalidade, o que indica uma relação com os achados da tonicidade dos músculos trapézios, elevadores primários da escápula (encolhimento dos ombros) (Hoppenfeld 1999).

Entretanto, a análise global dos dados evidencia que, na amostra avaliada, não foram detectadas alterações importantes de postura de cabeça nos dois períodos estudados, havendo a necessidade de ampliar o número de indivíduos avaliados para atingir conclusões mais consistentes. 
Conclusão 


\section{CONCLUSÃO}

Pode-se concluir, com o presente estudo, que não houve modificação na postura de cabeça após a cirurgia ortognática nos indivíduos com fissura labiopalatina e mordida cruzada total estudados. 


\section{Referências}

Bibliográficas 


\section{REFERÊNCIAS BIBLIOGRÁFICAS}

Angle EH (1907) apud Bianchini EMG. A Cefalometria nas alterações miofuncionais orais: diagnóstico e tratamento fonoaudiológico. 4a. ed. Carapicuíba: Pró-Fono; 1998.

Athanasiou AE, Toutountzakis N, Mavreas D, Ritzau M, Wenzel A. Alterations of hyoid bone position and pharyngeal depth and their relationship after surgical correction of mandibular prognathism. Am J Orthod Dentofacial Ortop 1991; 100:259-65.

Benech A, Fasciolo A, De Gioanni PP, Madaro E. Evaluation of the posture of patientes before and after orthodontic surgery. Minerva Stomatol 1997; 46: 43541.

Berretin-Felix G, Jorge TM, Genaro KF. Intervenção fonoaudiológica em pacientes submetidos à cirurgia ortognática. In: Picollotto L, Béfi-Lopes DM, Limongi SCO, organizadoras. Tratado de Fonoaudiologia. São Paulo: Roca; 2004. p.261-76.

Bricot B. Posturologia. tradução por Ângela Bushatsky. São Paulo: Ícone; 1999. Tradução de: A reprogrammation posturale globale.

Douglas CR. Tratado de fisiologia aplicada à Fonoaudiologia. São Paulo: Robe Editorial; 2002.

Farina D, Kallenberg LA, Merletti R, Hermens HJ. Effect of side dominance on myoelectric manifestations of muscle fatigue in the human upper trapezius muscle. Eur J Appl Physiol 2003; 90:480-8. 
Fuentes R, Freesmeyer W, Henríquez J. Influence of body posture in the prevalence of craniomandibular dysfunction. Rev Med Chil 1999; 127:1079-85.

Gelb H. New concepts in craniomandibular and chronic pain management. Barcelona: Espaxs; 1994.

Gonzales HE, Manns A. Forward head posture: It's structural and functional influence on stomatognathic sistem, a conceptual study. Cranio 1996; 14:71-80.

Goldstein DF, Kraus SL, Williams WB, Glaseen-Wray M. Influence of cervical posture on mandibular movement. J Prosthet Dent 1984; 52:421-6.

Hatch JP, Rugh JD, Clarck GM, Keeling SD, Tiner BD, Bays RA. Health-related quality of life following orthognathic surgery. Int $J$ Adult Orthodon Orthognath Surg 1998; 13:67-77.

Hoppenfeld S. Propedêutica ortopética - coluna e extremidades. tradução por: Antonio Augusto F. Quadra e Ingrid M. Xavier Vizeu. São Paulo: Atheneu; 1999. Tradução de: Physical examination of the spine and extremities.

Hruska Jr. RJ. Influences of dysfunction respiratory mechanics on orofacial pain. Dent Clin North Am 1997; 41:211-27.

Kendall FP, MacCreary KM, Provance PG. Postura: alinhamento e equilíbrio muscular. In: Kendall FP. Músculos: provas e funções. 4a. ed. São Paulo: Manole,1995. p.69-75.

Kinser C, Colby LA. Therapeutic exercise: foundations and techniques. Philadelphia: FA Davi; 1989.

Krakauer LRH. Relação entre respiração bucal e alterações posturais em crianças: uma análise descritiva. [dissertação]. São Paulo: Pontifícia Universidade Católica; 1997. 
Lima ECB, Gonçalves EC, Reis AC. Treino de postura em pacientes portadores de disfunções temporomandibulares. Reabilitar 2004; 6:55-9.

MacConkey D. Relationship of posture and dental health. Int $J$ Orofacial Myology 1991; 17:8-10.

Marques AP. Manual de Goniometria. São Paulo: Manole; 1997.

Michelotti A, Manzo P, Farella M, Martina R. Occlusion and posture; Is there evidence of correlation? Minerva Stomatol 1999; 48:525-34.

Milani RS, De Periere DD, Lapeyre L, Pourreyron L. Relationship between dental occlusion and posture. Cranio 2000; 18:127-34.

Motegi E, Hatch JP, Rugh JD, Yamaguchi H. Health-related quality of life and psychosocial function 5 years after orthognathic surgery. Am J Orthod Dentofacial Orthop 2003; 124:138-43.

Pahkala R, Heino J. Effects of sagittal split ramus osteotomy on temporomandibular disorders in seventy-two patients. Acta Odontol Scand $2004 ; 62: 238-44$.

Panula K, Somppi M, Finne K, Oikarinen K. Effects of orthognathic surgery on temporomandibular joint dysfunction. A controlled prospective 4-year follow-up study. Int J Oral Maxillofac Surg 2000; 29:183-7.

Peterlin BL, Ward TN. Neuropsychiatric aspects of migraine. Curr Psychiatry Rep 2005; 7:371-5.

Peterson LJ, Ellis E, Hupp JR, Tucker MR. Cirurgia oral e maxilofacial contemporânea. 3a. ed. tradução por Alexandre Wellos da Silva et al. Rio de Janeiro: Guanabara Koogan; 2000. Tradução de: Contemporary oral and maxillofacial surgery. 
Phillips C, Snow MD, Turvey TA, Proffit WR. The effect of orthognathic surgery on head posture. Eur J Orthod. 1991; 13:397-403.

Precious DS, Goodday RH, Morrison AD, Davis BR. Cleft lip and palate: a review for dentists. J Can Dent Assoc 2001; 67:668-73.

Raberin M. Muscular equilibrium and orthognathic surgery. A preliminary eletromiographic study. Orthod Fr 2000; 71:37-48.

Rocabado MS. Cabeza e cuello - Tratamiento articular. Buenos Aires: InterMedica; 1979.

Samman N, Tang SS, Xia J. Cephalometric study of the upper airway in surgically corrected Class III skeletal deformity. Int J Adult Orthodon Orthognath Surg 2002; 17:180-90.

San Juan Zamora MA, Yáñez MM. Posición mandibular em pacientes sometidos a terapia kinésica de cuarto superior. Rev Fac Odontol Valparaíso 1999; 2:201-8.

Schellino E, Oria A, Fornengo B. Postural changes of the tongue and hyiod bone following orthognathodontic surgical interventions. Minerva Stomatol 1991; 40:405-8.

Solow B, Sonnesen L. Head posture and malocclusions. Eur J Orthod 1998; 20:685-93.

Souza CCM, Campiotto AR, Freitas RR. Cirurgia ortognática e fonoaudiologia. In: Lopes Filho O. Tratado de Fonoaudiologia. São Paulo: Roca; 1997. p.781804. 
Tanaka C, Farah E. Anatomia funcional das cadeias musculares. São Paulo: Ícone; 1997.

Tessitori A. Alterações oromiofuncionais em respiradores orais. In: Picollotto L, Béfi-Lopes DM, Limongi O, organizadoras. Tratado de Fonoaudiologia. São Paulo: Roca; 2004. p.261-76.

Tome MC, Niemeyer TC, Gomes AOC, Fukushiro AP, Trindade Junior AS. Determinação do tônus muscular do músculo orbicular da boca de pacientes com fissura transforame incisivo unilateral reparada. In: Anais do $V$ Encontro Científico de Pós-Graduação; 2003 21-23 nov; Bauru, Brasil. Bauru: Hospital de Reabilitação de Anomalias Craniofaciais - Universidade de São Paulo; 2003. p.30.

Trindade IEK, Yamashita RP, Suguimoto RM, Mazzottini R, Trindade Junior AS. Effects of orthognathic surgery on speech and breathing of subjects eith cleft lip and palate: acoustic and aerodynamic assessment. Cleft Palate Craniofac $J$ 2003; 40:54-64.

van der Braber W, van der Glas $\mathrm{H}$, van der Bilt A, Bosman F. Masticatory function in retrognathic patients, before and after mandibular advancement surgery. J Oral Maxillofac Surg 2004; 62:549-54.

Vig OS, Showfety KJ, Phillips C. Experimental manipulation of head posture. Am J Orthod 1980; 77:258-68.

Wenzel A, Williams S, Ritzau M. Changes in head posture and nasopharyngeal airway following surgical correction of mandibular prognathism. Eur $\mathrm{J}$ Orthod 1989; 11:37-42.

Zemlin W. Princípios de anatomia e fisiologia em Fonoaudiologia. 4a. ed. Porto Alegre: Artmed; 2000. 
Anexos 


\section{ANEXO 1 - Aprovação do Comitê de Ética em Pesquisa em Seres Humanos do HRAC-USP}

Oficio $n^{\circ}$ 058/2004-UEP-CEP

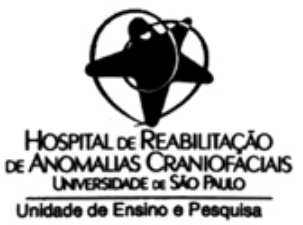

Bauru, 03 de maio de 2004.

Prezado(a) Senhor(a)

O projeto de pesquisa encaminhado a este Comitê de Ética em Pesquisa em Seres Humanos, denominado "Cirurgia ortognática e postura de cabeça", de autoria de VERA MARIA TELLES NUNES, desenvolvido sob sua orientação, foi enviado ao relator para avaliação.

Na reunião de 28 de abril de 2004 o parecer do relator, aprovando o projeto, foi aceito pelo Comitê, considerando que não existem infrações éticas pendentes para início da pesquisa. Solicitamos a V.S` a gentileza de comunicar o parecer à pesquisadora.

A pesquisadora fica responsável pela entrega na Unidade de Ensino e Pesquisa dos relatórios semestrais.

Informamos que após o recebimento do trabalho concluído, este Comitê enviará o parecer final para publicação.

\section{Atenciosamente}

\section{PROF. DR. ROBERTO LOUREIRO MARINGONI}

Coordenador do Comitê de Ética em Pesquisa do HRAC-USP

Ilmo(a) Sr(a)

Prof. Dr. Alceu Sérgio Trindade Júnior

Fisiologia - HRAC/USP

rua Silvio Marchione, 3-20 Bauru SP Brasil 
ANEXO 2- Carta de informação ao sujeito da Pesquisa

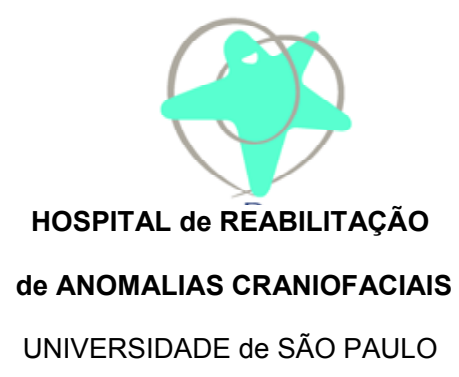

\section{CARTA DE INFORMAÇÂO AO SUJEITO DA PESQUISA Cirurgia Ortognática e Postura de Cabeça}

$\operatorname{Sr}(a)$. Paciente ou responsável:

Nossa pesquisa tem por objetivo avaliar a posição da cabeça em jovens e adultos antes (três dias) e após (de três a seis meses) a realização da cirurgia ortognática no HRAC/USP.

As avaliações serão realizadas no LABORATÖRIO DE FISIOLOGIA do HRAC/USP(CENTRINHO), pela fisioterapeuta responsável pela pesquisa Vera Maria Telles Nunes, nos mesmos dias dos atendimentos agendados previamente para este setor, não havendo necessidade de comparecer ao hospital somente para este atendimento.

A postura (posição) da cabeça será avaliada por meio de observação visual e de palpação suave dos músculos da face, pescoço e ombros, sendo necessário despir a blusa ou a camisa, estando sempre o paciente acompanhado de um familiar ou outro profissional do setor.

A avaliação será rápida e não causará dor ou desconforto ao paciente.

Na divulgação dos dados da pesquisa a sua identidade será mantida em sigilo.Qualquer dúvida poderá ser por nós esclarecida pessoalmente ou pelo telefone (14) 3235-8137. Caso queira apresentar reclamações em relação a sua participação na pesquisa, poderá entrar em contato com o Comitê de Ética em Pesquisa em Seres Humanos do HRAC/USP, no endereço Rua Silvio Marchione 3-20 ou pelo telefone (14) 3235-8421.

Vera Maria Telles Nunes

Pesquisadora

Vera Maria Telles Nunes

Rua Antonio dos Reis n 4-67 Higienópolis- Bauru fone(14) 32344312 


\section{TERMO DE CONSENTIMENTO LIVRE E ESCLARECIDO}

EU, portador de RG No residente à Rua $(\mathrm{Av}$. $\mathrm{N}^{\circ}$ , na cidade de Estado

(responsável pelo(a) menor )$^{*}$ matriculado no HRAC com o $\mathrm{N}^{\circ}$ concordo em participar na (autorizo a sua participação na )* pesquisa de título: "Cirurgia Ortognática e Postura de Cabeça", realizada por: Vera Maria Telles Nunes $\mathrm{N}^{\circ}$ do conselho $\underline{\text { Crefito }}$ $1589-F$, sob orientação do Prof. Dr. Alceu Sérgio Trindade Júnior $N^{\circ}$ do conselho CRO - 10843.

A referida pesquisa será realizada no Laboratório de Fisiologia do HRAC-USP para comparar se houve modificação em minha postura (posição) de cabeça após a cirurgia ortognática.

Serei submetido a avaliação postural (de posição) de minha cabeça antes e após a cirurgia ortognática por meio de palpação muscular da face, pescoço e ombros, sempre na presença de um familiar ou outro profissional do departamento.

Para que seja avaliada minha condição muscular e postural, terei que despir a blusa ou a camisa.

Os retornos serão nos mesmos dias previamente agendados não havendo necessidade de voltar ao Hospital apenas para este atendimento.

Estou ciente de que minha participação é voluntária e dela posso desistir a qualquer momento, sem explicar os motivos e sem comprometer o meu tratamento no HRAC-USP.

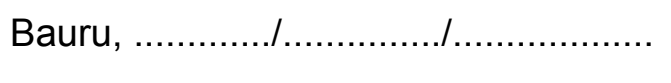

Assinatura paciente ou responsável

Nome pesquisador responsável: Vera Maria Telles Nunes

Endereço institucional: Rua Silvio Marchione No 3-20

Cidade: Bauru Estado: SP Cep: 17043-900

Telefone: (14) 3235-8066 


\section{ANEXO 4 - TERMO DE CONCORDÂNCIA}

Divulgação de imagens

HOSPITAL de REABILITAÇÃO de ANOMALIAS CRANIOFACIAIS

UNIVERSIDADE de SÃO PAULO

\section{TERMO DE CONCORDÂNCIA}

Divulgação de imagens

Eu,

portador do RG $\mathrm{n}^{\circ}$ autorizo o Hospital de

Reabilitação de Anomalias Craniofaciais - HRAC/USP a divulgar e publicar imagens referentes à pesquisa de Mestrado "Cirurgia ortognática e postura de cabeça”, realizada pela fisioterapeuta Vera Maria Telles Nunes, $\mathrm{n}^{\circ}$ do Conselho CREFITO 1589-F, sob orientação do Prof. Dr. Alceu Sérgio Trindade Júnior, $\mathrm{n}^{\circ}$ do Conselho CRO 10843, da qual participei como voluntário.

Entendo que este material pode ser utilizado para fins de publicações e eventos científicos e atividades didáticas, sem identificação nominal.

Assinatura do voluntário

Bauru, de de 2005. 


\section{ANEXO 5- Protocolo de Avaliação}

HOSPITAL DE REABILITACÃO DE ANOMALIAS CRANIOFACIAIS UNIVERSIDADE dE SĀO PAULO

\section{AVALIAÇÃO DA POSTURA CORPORAL}

1. IDENTIFICAÇÃO

Nome:
RG: Hospital:

Setor:

Gênero:

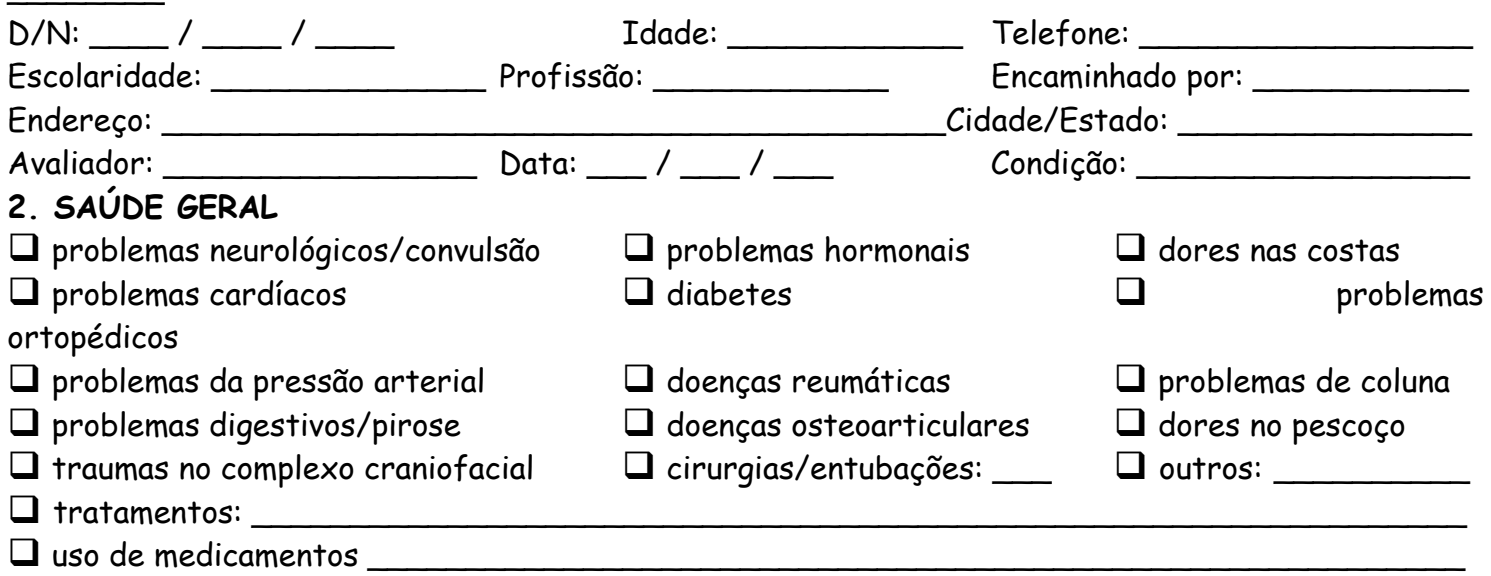

\section{AVALIAÇÃO DA CABEÇA E COLUNA CERVICAL}

\subsection{Linha Bipupilar:}

$\square$ normal

3.2 Cabeça Face Anterior:

$\square$ Centralizada

3.3 Cabeça Face Lateral:

$\square$ Normal

3.4 Coluna Cervical:

$\square$ Lordose Fisiológica

3.5 Tônus: (-2 hipotonia hipertonia)

Masseter: $D$<smiles>[3H]C</smiles>

$\square$ alterada

$\square$ Rodada

Inclinada Lateral

\section{$\square$ Extensão}

$\square$ Flexão

$\square$ Protrusão

Retificação da Lordose

$\square$ Hiperlordose Cervical -1 hipotonialeve 0 normotonia +1 hipertonialeve +2

Trapézio: $D$

\section{$\mathrm{E}$}

Esternocleidomastoídeo $D$

3.6 Mobilidade Ativa da Cabeça: Normal Limitada

$\begin{array}{lcc}\text { Flexão: } & \square & \square \\ \text { Extensão: } & \square & \square \\ \text { Rotação D: } & \square & \square \\ \text { Rotação E: } & \square & \square \\ \text { Inclinação lateral D: } & \square & \square \\ \text { Inclinação lateral E: } & \square & \square\end{array}$

3.7 Dor à palpação:

$\begin{array}{ccccc}\text { Masseter } & \text { Temporal } & \text { Trapézio } & \text { ATM } & \text { Esternocleidomastóideo } \\ \square D & \square D & \square D & \square D & \square D \\ \square E & \square E & \square E & \square E & \square E\end{array}$

3.8 Altura dos Ombros:

$\square$ normal

$\square$ alterado 